\title{
CONCESIONES VIALES DE CUARTA GENERACIÓN (4G): UNA ESTIMACIÓN DE SU IMPACTO ECONÓMICO Y SOCIAL
}

\author{
RAÚL CASTRO RODRÍGUEZ \\ Facultad de Economía, Universidad de los Andes, Bogotá, Colombia \\ HUMBERTO BERNAL CASTRO \\ Facultad de Economía, Universidad Colegio Mayor de \\ Cundinamarca, Bogotá, Colombia
}

\section{RESU MEN}

Este artículo presenta metodologías y aplicaciones como estudio de caso para cuantificar el impacto económico y social de las concesiones $4 \mathrm{G}$ en Colombia. Para el impacto económico se utilizaron los Multiplicadores Leontief derivados de la Matriz Insumo Producto la cual se construye para el estudio de caso de la Matriz Utilización Desagregada en Productos Nacionales e Importados reportada por el DANE. Estos multiplicadores permiten estimar la contribución de estos proyectos al crecimiento económico. El impacto social se analizó mediante el Índice de Pobreza Monetaria y el Índice de Pobreza Multidimensional con la información reportada en la Gran Encuesta Integrada de Hogares. Como estudio de caso para la aplicación de la metodología se utilizó el corredor Santana-Puerto Salgar localizado en Colombia. Los resultados generados por los Multiplicadores Leontief permiten calcular que por cada COP $\$ 1,0$ invertido en las concesiones $4 \mathrm{G}$, se generan $\mathrm{COP} \$ 2,52$ en términos brutos y COP $\$ 1,52$ en términos netos. Este efecto multiplicativo genera un aporte al crecimiento del PIB nacional del 0,27\%, 017\% y 0,01\% para los años 2018, 2019 y 2020

Los autores agradecen a funcionarios e investigadores del Departamento Nacional de Planeación, a la Agencia Nacional de Infraestructura y al Centro Nacional de Consultoría por facilitar información, y proporcionar sugerencias y comentarios a una versión anterior. También agradecen los comentarios de Jorge Armando Rueda, de los pares evaluadores anónimos y de la dirección de la revista Economía \& Región. Las opiniones expresadas en esta publicación son responsabilidad exclusiva de los autores y no necesariamente reflejan el punto de vista las anteriores entidades. Correo electrónico: Raúl Castro Rodríguez, rcastro@ uniandes.edu.co. Recibido: 16 de septiembre de 2019; aceptado: 27 de noviembre de 2019.

Econamía\&Regón Vd. 13, Nb. 2, (Gartagena, dicientre2019), pp 9-56 
respectivamente, durante la etapa de construcción, y 0,04\% anual entre 2022 y 2024 durante la etapa de operación del corredor. El impacto social se cuantificó mediante la reducción del número de personas pobres en los departamentos afectados; se espera una reducción del Índice de Pobreza Monetaria de 32,1\% a $23,2 \%$ durante la etapa de construcción y operación, y una reducción de $12,4 \%$ a 10,2\% del Índice de Pobreza Multidimensional para el mismo periodo.

Palabras claves: Concesiones 4G, Multiplicadores Leontief, Pobreza Monetaria, Pobreza Multidimensional

Clasificaciones JEL: D04, D31, D57

\section{ABST RACT}

\section{Fourth generation (4G) road licenses: an estimate of its economic and social consequences}

This paper concerns a set of methodologies and applications, as a case study to measure the economic and social consequences of implementing fourthgeneration $(4 \mathrm{G})$ road licenses in Colombia. For the economic estimates, we used Leontief Multipliers derived from the Input Output Matrix which is put together for the case study of the Disaggregated Utilization Matrix in National and Imported Products reported by DANE. These multipliers allow the estimation of the projects' contribution to economic growth. The social effect is analyzed using the Monetary Poverty Index and the Multidimensional Poverty Index using the information reported in the Large Integrated Household Survey. As a case study for the application of the methodology, the Santana-Puerto Salgar corridor located in Colombia is used. The results generated by the Leontief Multipliers allow us to calculate that for each COP $\$ 1.0$ invested in the $4 \mathrm{G}$ concessions, COP $\$ 2.52$ is generated in gross terms and COP $\$ 1.52$ in net terms. This multiplicative effect generates a contribution to the national GDP growth of $0.27 \%, 0.17 \%$ and $0.01 \%$ for the years 2018,2019 and 2020 respectively, during the construction phase, and $0.04 \%$ per year between 2022 and 2024 during the operation stage. The social impact is quantified through the reduction of the number of poor people in the affected departments; a reduction of the Monetary Poverty Index is expected from $32.1 \%$ to $23.2 \%$ during the construction and operation phase, and a reduction from $12.4 \%$ to $10.2 \%$ of the Multidimensional 
Poverty Index for the same period.

Key Words: 4G licenses, Leontief multipliers, Monetary poverty, Multidimensional poverty

JEL Codes: D04, D31, D57

\section{INTRODUCCIÓN}

Las concesiones viales de cuarta generación (4G) representan un ambicioso programa de desarrollo de la infraestructura vial de Colombia para el periodo comprendido entre 2012 y 2020, que plantea la construcción y operación en concesión de más de $8.000 \mathrm{~km}$ de autopistas, que incluyen $1.370 \mathrm{~km}$ de doble calzadas, 159 túneles y 1.300 viaductos en más de 40 nuevas concesiones, de las cuales (a noviembre de 2018) 30 están adjudicadas. La inversión estimada es de COP $\$ 47$ billones, 5,4\% del PIB del 2016 en Colombia (USD $\$ 18.000$ millones). El objetivo de las concesiones de $4 \mathrm{G}$ es reducir los costos generalizados de viaje en los componentes de costos de operación vehicular y de tiempo de viaje, tanto para transporte de carga como de personas, todo con el propósito de mejorar la competitividad de la economía colombiana.

Este estudio plantea una metodología que permite cuantificar el impacto económico y social generado por la construcción y puesta en operación de las concesiones 4G. La metodología usada para la parte económica consistió de los Multiplicadores Leontief derivados de la Matriz Insumo Producto (MIP). Esta MIP es deducida de la Matriz Utilización Desagregada en Productos Nacionales e Importados reportada por el DANE. A su vez, esta matriz se construye a partir del "cuadro oferta-utilización, que describe el proceso productivo a través de la interrelación de actividades y productos" como lo señala DANE (2018).

Para valorar el impacto social se usó la variación ocurrida en el Índice de Pobreza Monetario y el Índice de Pobreza Multidimensional como consecuencia del programa.

El estudio de caso al que se aplica esta metodología es la concesión 4G en el corredor Santana-Puerto Salgar (que abarca los departamentos de Caldas, Cauca, Cundinamarca, Huila y Tolima). Se toma este corredor como estudio de caso para señalar la metodología empleada, que puede ser repetida sin dificultades en cualquier otro corredor de las autopistas $4 \mathrm{G}$ (e.g. autopistas del

\footnotetext{
${ }^{1}$ Agencia Nacional de Infraestructura, ANI(2015).
} 
Pacífico, autopista Villavicencio-Yopal, entre otras).

El documento está dividido en cinco secciones, la primera siendo la introducción, la segunda presenta una descripción global del programa de las concesiones $4 \mathrm{G}$ con una revisión de literatura, la tercera y cuarta secciones describen respectivamente la metodología para medir el impacto económico y social del programa y su aplicación al estudio de caso, y la quinta sección presenta las principales conclusiones y recomendaciones.

\section{VÍAS DE CUARTA GENERACIÓN: CONCESIONES VIALES DE COLOMBIA}

Desde 2012 se han venido adjudicando contratos público-privados para mejorar la infraestructura vial con el fin de mejorar la conectividad y la competitividad de Colombia. Estos proyectos se conocen como vías Cuarta Generación de Concesiones Viales de Colombia (4G). Entre los proyectos adjudicados están los corredores viales: Autopista Conexión Pacífico, Autopista Villavicencio-Yopal, Autopista Santana-Puerto Salgar entre otros (ANI, 2015).

Una mejor competitividad representa, entre otros aspectos, un mayor volumen de bienes y servicios transados en una economía, indicador que a su vez se refleja en un aumento en el PIB. De igual forma, se usaron otros indicadores que permiten cuantificar el impacto sobre la competitividad como la variación en la productividad y en la tasa de desempleo. Para el caso del impacto social, los indicadores relevantes usados fueron los índices de variación de la pobreza.

\section{A. Literatura relacionada}

La literatura de utilización de matrices insumo producto para estimar la contribución que tiene alguna de las variables de la demanda agregada (i.e. inversión, consumo, exportaciones, entre otros) sobre el producto interno bruto de un país es bastante amplia, destacándose en particular los trabajos de las Naciones Unidas y de la Comunidad Europea, United Nations (2018) y Eurostat (2008), que presentan el uso y aplicación de las Tablas Insumo Producto (Matrices Insumo Producto, MIP) para países desarrollados o en vías de desarrollo, tales como Canadá, Noruega, Reino Unido, Chile, Estados Unidos, entre otros. Por un lado, la metodología del presente trabajo es similar y también sigue 
de cerca la de Miller y Blair (2009). Por otro lado, Nguyen y Shimizu (2017) presentan la aplicación del uso de Tablas Insumo-Producto para estimar el impacto del turismo y del transporte turístico en la economía japonesa. El documento de Nguyen y Shimizu (2017) resalta la importancia del uso de estas tablas y sus multiplicadores para investigar la influencia del transporte sobre el turismo en Japón. El estudio realizado por Bui (2016) presenta tanto la metodología para analizar las Tablas Insumo-Producto, como su aplicación sobre la economía de Vietnam, y dentro de sus objetivos esta el análisis del impacto de la construcción de infraestructura sobre las cuentas nacionales de Vietnam, con resultados que son positivos y satisfactorios mediante los Multiplicadores Leontief. Finalmente, Bon (2000) presenta la pertinencia del uso de las Tablas Insumo-Producto (MIP) usando diferentes estudios de caso en Italia, Japón, Reino Unido y Estados Unidos, cada uno enfocándose en un subsector de la economía.

Se puede concluir que la aplicación de las Tablas Insumo-Producto (Matrices Insumo Producto) y sus derivados, los Multiplicadores Leontief, son relevantes para cuantificar impactos económicos y para la toma de decisiones económicas. Por tanto, se justifica aplicar esta metodología con sus variantes específicas del presente estudio, para estimar la contribución al impacto económico de la construcción y operación de las autopistas viales $4 \mathrm{G}$.

La literatura local sobre la cuantificación del impacto económico y social relacionado con la construcción y puesta en operación de los corredores viales $4 \mathrm{G}$ es variada. Por una parte, Clavijo (2016) señaló que el crecimiento adicional esperado del PIB real será de 0,2\% por año durante el lapso del 2016 al 2020 debido a la construcción de las concesiones 4G. De igual forma, señala que para la primera ola del proyecto se genera un crecimiento del 0,18\% adicional del PIB real, y se presenta en dos partes: la primera parte se fija en un 0,12\% que tendrá efecto mediante la inversión directa en obras civiles; la segunda parte del efecto se da en $0,06 \%$, indirectamente, por medio del encadenamiento productivo liderado por sectores de comercio, la industria y la maquinaria. Por otra parte, Ramírez y Villar (2015), investigadores de Fedesarrollo, argumentaron que para los años 2016 y 2017 se esperaría un aumento del PIB en 2\% y 1,9\% respectivamente, y una elevada contribución del sector infraestructura debido a las concesiones $4 \mathrm{G}$. En efecto, el crecimiento registrado fue de $2 \%$ y $1,8 \%$, en su orden. La ANI y el DNP (2014) señalaron que las proyecciones para la tasa de desempleo se iban a ubicar por debajo de un $8 \%$, lo que implica la creación de 180.000 empleos directos; con esta cifra las concesiones contribuyen en gran medida a la reducción del desempleo. Además, DNP (2014) señaló que por medio de los proyectos de construcción de infraestructura vial $4 \mathrm{G}$ se iba a 
lograr una reducción del 30\% en los tiempos de desplazamiento entre puertos y centros productivos, al igual que de los costos operacionales de los vehículos en un 20\%, lo que aumentaría la productividad alrededor del sector transporte e indirectamente en el sector agrícola. Asimismo, el DNP (2014) argumentó que las vías $4 \mathrm{G}$ iban a permitir un aumento en la productividad total de los factores, la cual se estimó que iba a pasar de $0,7 \%$ a tasas de entre $1 \%$ y $1,3 \%$ para los años 2019 y 2024. Ahora, en el estudio realizado por la Universidad Pontificia Bolivariana y la Universidad de Antioquia (Lotero y Londoño, 2015) se estimó que la inversión anual en las Autopistas, que era de alrededor COP $\$ 2$ billones a precios del 2012 en Antioquia, contribuiría con un 3,7\% adicional al crecimiento del PIB del departamento, al elevar la tasa anual de crecimiento del PIB en una magnitud superior al 7,0\%. En términos de empleo se generarían más de 190.000 puestos de trabajo en toda la economía colombiana durante el tiempo de la construcción de las autopistas, lo que se traduciría en una caída de la tasa de desocupación a un nivel cercano del 5,0\%.

Dentro de la literatura referente al impacto social de las $4 \mathrm{G}$ se destacan los documentos Conpes Social 150 y el Panorámica Regional por el DNP (2017), que definen una metodología para calcular la pobreza multidimensional ajustada a partir de la Gran Encuesta Integrada de Hogares. De igual forma Ramírez y Villar (2014) han sugerido para el departamento de Antioquia que la densidad de malla vial por kilómetro cuadrado incide en sus niveles de pobreza. Específicamente, estiman que ante un aumento de 10,0\% en el número de kilómetros de vías terciarias por kilómetro cuadrado, se disminuye en $5 \%$ la tasa de pobreza multidimensional en el ámbito rural del departamento.

Finalmente, Ramírez (2018) presenta la metodología del Instituto de Estrategia y Competitividad de la Universidad de Harvard, "que establece que el mayor valor económico generado por las empresas -en particular las 4Gdepende de tres factores: ambiente de negocios, presencia de clústeres y nivel de sofisticación de las estrategias y operaciones de las empresas"; se trata de un estudio de competitividad regional, enfoque diferente al del presente trabajo que es de valoración de la contribución económica a nivel nacional.

\section{IMPACTO ECONÓMICO DE LAS CONCESIONES 4G}

La propuesta en este documento para medir el impacto económico del programa de concesiones $4 \mathrm{G}$ y sus efectos intersectoriales a nivel nacional es el enfoque Insumo-Producto. La cuantificación de los beneficios económicos 
a nivel nacional se calcula a partir del incremento en el Valor Agregado (VA) Intersectorial, como consecuencia de la inversión realizada durante la etapa de construcción y operación en el corredor vial 4G. La metodología empleada en el enfoque parte de la derivación de los Multiplicadores Leontief ${ }^{2}$ de la MIP. Para el estudio de caso se utilizó la MIP construida a partir de la Matriz Utilización Desagregada en Productos Nacionales e Importados suministrada por el DANE. Esta matriz se reporta para los sectores económicos, sin embargo, no se cuenta con información desagregada a nivel departamental o municipal que permita realizar una cuantificación diferenciada según departamento o municipio.

\section{A. Multiplicadores Leontief}

El enfoque insumo producto parte de la construcción de MIP que registra todas las transacciones realizadas por una economía durante un período, usualmente de un año. Dentro de las principales características de los datos registrados en esta matriz están las compras y ventas intermedias realizadas entre las diferentes actividades económicas; a nivel ilustrativo el Cuadro 1 presenta las celdas que corresponden a las transacciones de cada una de las actividades económicas; así, la posición $(1,2)$ (fila 1 , columna 2) corresponde a las ventas realizadas por el sector agrícola al sector industrial; de igual forma, se puede determinar la demanda final de cada uno de los sectores de la economía, al igual que su valor agregado (VA).

A partir de la MIP, en particular la de consumo intermedio-productor, se pueden calcular los Multiplicadores de la Oferta (Multiplicadores Leontief ${ }^{3}$ ) debido a impactos exógenos sobre la demanda, representados en particular por la ecuación (1):

$$
\Delta X=(I-A)^{-1} \Delta f
$$

Donde:

$\Delta X$ : Variación de los elementos de un vector columna $(n \times 1)$ referentes a la oferta de cada una de las $n$ actividades de la economía (i.e. agricultura, industria, comercio, infraestructura, entre otros) ante cambios en la demanda final de estos sectores, en este caso la inversión en infraestructura vial.

$A$ : es la matriz $(n \times n)$ de coeficientes técnicos de Leontief.

\footnotetext{
${ }^{2}$ Miller y Blair (2009) presentan en detalle el desarrollo teórico del enfoque insumo-producto.
}

${ }^{3}$ El Anexo A amplía detalles de la metodología. 


\section{CUADRO 1}

Esquema de una Matriz Insumo-Producto

\begin{tabular}{|c|c|c|c|c|c|c|c|c|c|}
\hline & & & onsumo & ntermedic & & & Dem & inda final & \\
\hline & Sector & Agrícola & Industria & Comercio & Minería & Hogares & Gobierno & Inversión & $\begin{array}{l}\text { Exportaciones } \\
\text { netas }\end{array}$ \\
\hline \multirow{4}{*}{$\begin{array}{l}0 \\
0 \\
0 \\
0 \\
0 \\
0 \\
0\end{array}$} & Agrícola & & & & & & & & \\
\hline & Industria & & & & & & & & \\
\hline & Comercio & & & & & & & & \\
\hline & Minería & & & & & & & & \\
\hline \multirow{3}{*}{ 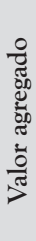 } & $\begin{array}{c}\text { Remuneración } \\
\text { asalariados }\end{array}$ & & & & & \multirow{3}{*}{\multicolumn{4}{|c|}{ Producto Interno Bruto }} \\
\hline & $\begin{array}{l}\text { Remuneración } \\
\text { al capital }\end{array}$ & & & & & & & & \\
\hline & $\begin{array}{l}\text { Impuestos } \\
\text { netos }\end{array}$ & & & & & & & & \\
\hline
\end{tabular}

Fuente: Elaboración del autor.

$\Delta f$ : Es el vector columna $(n \times 1)$ que incorpora la variación (cambio) de la demanda final (inversión en nuestro caso) realizada por los hogares, gobierno, inversionistas o exportadores en cada uno de los n sectores de la economía.

\section{B. Interpretación de los multiplicadores Leontief y su impacto en el valor agregado}

Los Multiplicadores de la Oferta, también conocidos como multiplicadores de la producción del sector debido a impactos en la demanda, son elementos de la matriz inversa de Leontief, $m=(I-A)^{-1}$, que generan información sobre las necesidades de oferta para satisfacer el incremento de demanda exógena de uno o de varios sectores incluidos en la MIP. Por ejemplo, en una economía con tres sectores: agricultura, industria y servicios, si se genera un incremento exógeno en la demanda de servicios (mayor inversión), entonces los tres sectores deben producir bienes y servicios para satisfacer esta necesidad exógena del sector servicios. De igual forma, se puede generar un incremento exógeno simultáneo en los tres sectores, y por tanto estos deben reaccionar con producción (oferta) para satisfacer las demandas exógenas de los tres sectores. Estos multiplicadores 
representan todos los requerimientos directos e indirectos de este cambio. La literatura es amplia de resultados obtenidos con el uso de Multiplicadores Leontief, y una buena síntesis puede encontrarse, entre otros, en Hernández (2012), Miller y Blair (2009) y Burgos (2007).

Con esta metodología se muestra el incremento del valor agregado (VA) del total de la economía, originado por la inversión en el proyecto (o programa) mediante la sumatoria de cada uno de los impactos sectoriales reportados en $\Delta X$.

Para el cálculo de la contribución al crecimiento económico, se debe tener en cuenta esta sumatoria y su participación en el crecimiento. En particular, para determinar el impacto sobre el PIB de 2017, se desagregan en la siguiente ecuación los componentes generales del PIB en términos de VA en la producción (i.e. remuneración al empleo, remuneración al capital, entre otros) variable que incorpora el cambio generado por la demanda exógena (producto de la inversión en la construcción y mantenimiento de las concesiones $4 \mathrm{G}$ ); para el análisis se resalta que metodológicamente se mantienen constantes el Impuesto al Valor Agregado (IVA), los aranceles, los otros impuestos y las subvenciones:

$$
P I B_{2017}=V A_{2017}^{57}+I V A_{2017}+\text { Aranceles }_{2017}+\text { Otros Impuestos }_{2017}-\text { Subvensiones }_{2017}
$$

Donde:

$V A_{t}^{57}$ : Sumatoria del valor agregado de los 57 sectores.

La Matriz Utilización Desagregada en Productos Nacionales e Importados del DANE presenta 61 actividades económicas que se reducen a 57 para evitar que la matriz sea singular (determinante nulo) y así poder medir los Multiplicadores Leontief.

A través de los resultados obtenidos por la aplicación de los Multiplicadores Leontief se calcula el impacto sobre el $V A\left(\Delta X_{2017}=\Delta V A_{2017}^{57}\right)$.

Con esta expresión se calcula adicionalmente el incremento porcentual en el VA relacionado con el aumento exógeno en la demanda, en particular, el aumento de la inversión en el sector construcción. Para el año de análisis, 2017, la expresión es: $\left(\frac{\Delta V A A_{0217}^{507}}{V A_{2017}^{5017}}\right) * 100$.

Finalmente y teniendo en cuenta que el PIB total es la sumatoria de los PIB 
sectoriales más los impuestos indirectos pagados por mercancías importadas, para calcular el aporte al crecimiento del PIB total asociado con el impacto exógeno en la demanda, se debe ponderar el crecimiento porcentual $\left(\frac{\Delta V A=17}{V A_{2017}^{57}}\right) * 100$ por la participación del VA (PIB sectoriales) sobre el PIB total. Formalmente:

$$
\frac{\Delta P I B_{2017}}{P I B_{2016}} * 100=\frac{V A_{2016}^{57}}{P I B_{2016}}\left(\frac{\Delta V A_{2017}^{57}}{V A_{2016}^{57}}\right) * 100
$$

\section{Manejo de datos multiplicadores Leontief}

La información para estimar el impacto en la economía asociado a la construcción y puesta en operación de las concesiones 4G parten de la Matriz Utilización Desagregada en Productos Nacionales e Importados 2015 del DANE y se usa como lo señala DANE (2018). Esta matriz se modifica y se agrega para aquellos sectores que no presentan suficientes transacciones intermedias como Desperdicios y Desechos (sector 37), Comercio (sector 43), Servicios Asociados (sector 60) y Servicios Domésticos (sector 63). El procedimiento de modificar la matriz consiste de adicionar cada uno de estos sectores al sector que lo antecede; por ejemplo, el sector Otros Bienes Manufacturados n.p.c (sector 36) ahora contiene al sector Desperdicios y Desechos (sector 37). Esta modificación se realiza tanto para las ventas (horizontal) como paras las compras (vertical), de manera que la matriz pasa de 61 sectores a 57.

Los datos de la inversión durante las etapas de construcción y de operación son suministrados por la Agencia Nacional de Infraestructura (ANI) y se aplican al sector "Trabajos de construcción, construcción de obras civiles y servicios de arrendamiento de equipo con operario". Los valores se transforman a precios constantes de 2015 usando el deflactor implícito del PIB que calcula el DANE. Además, se usa la estimación del crecimiento del PIB realizada por entidades gubernamentales para calcular el impacto total.

\section{Resultados de la contribución al PIB multiplicadores Leontief etapa de inversión}

El Corredor Santana-Puerto Salgar está dividido en tres proyectos: proyecto 1, asociado a la inversión y mantenimiento del corredor Santana-Mocoa-Neiva; proyecto 2, asociado a la inversión y mantenimiento del corredor Neiva-Espinal- 
Girardot, y el proyecto 3, relativo a la inversión y mantenimiento del corredor Girardot-Honda-Puerto Salgar. El proyecto 1 está ubicado en el suroccidente de Colombia, y abarca una distancia aproximada de $447 \mathrm{~km}$ como se aprecia en el Mapa 1. El costo económico de su inversión (construcción) es de COP\$3.614.831 millones según la ANI (2015). A continuación, se presenta el impacto de cada uno de los proyectos, pero desagregando solo el del proyecto 1 .

\section{MAPA 1}

Municipios del proyecto 1 del Corredor Santana-Puerto Salgar

\section{a Corredor 1}

Fuente: Elaboración propia, con base en información suministrada por DNP y ANI.

La anualización de los costos de inversión para el proyecto 1 se presenta en el Gráfico 1. En este caso, para el logro de los resultados se parte, como principal supuesto, del cumplimiento anual de la inversión según el cronograma que se refleja en los costos económicos. También está sujeta a la ausencia de impactos negativos en la economía, lo que se recoge en la proyección del PIB nacional realizada por entidades gubernamentales, pues esta proyección incorpora el crecimiento debido a la inversión en la concesión. 


\section{GRÁFICO 1}

Costo económico de la inversión en el proyecto 1

(millones de pesos constantes de 2015)

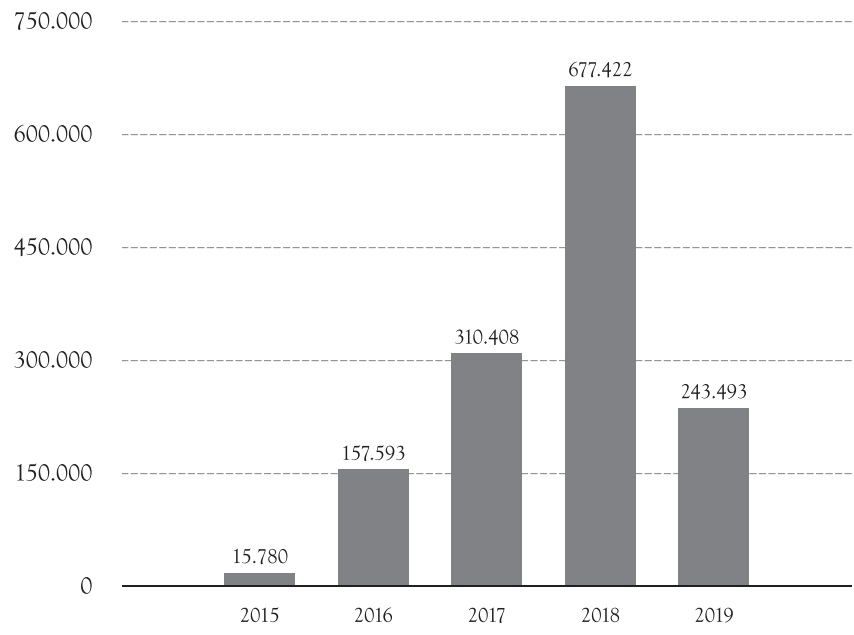

Fuente: Elaboración propia, con base en información suministrada por DNP y ANI.

Como se indicó, el efecto económico anual asociado con la inversión para el proyecto 1 se estimó con los Multiplicadores Leontief que permiten calcular el incremento en el crecimiento económico real. El multiplicador agregado de oferta en términos brutos por cada COP $\$ 1,0$ invertido es de 2,52, mientras que en términos netos es de $1,52 .{ }^{4}$ Se resalta que este multiplicador agregado es la sumatoria de cada multiplicador individual según sector, es decir, cada sector presenta su multiplicador y en términos agregados el impacto es de 2,52. El resultado aplica para los demás proyectos, pues el impacto se mide a nivel nacional y la metodología contempla el monto de la inversión durante esta etapa, mas no la ubicación. Esta situación implica que si la inversión es de COP $\$ 310.408$ millones durante el 2017, se espera un impacto bruto en la economía de COP $\$ 783.326$ millones, 0,09\% del crecimiento del PIB en 20175,

\footnotetext{
${ }^{4}$ La información para la obtención de los multiplicadores proviene de la Matriz Insumo-Producto que se deriva de la Matriz Utilización Desagregada en Productos Nacionales e Importados del DANE, con los ajustes señalados anteriormente; de igual forma se usó la estimación del PIB realizada por el DNP para calcular las participaciones respectivas. El cálculo de los multiplicadores se escribió en MATLAB.

${ }^{5}$ La inversión que se contempla en la etapa de construcción se asocia con el Capex y, para la etapa de operación, con el Opex.
} 
aplicando el procedimiento señalado previamente:

$$
\begin{gathered}
\Delta X_{2017}=2,5235(310.4078) \cong 783.326 \\
\frac{\Delta P I B_{2017}}{P I B_{2016}} 100=\frac{V A_{2016}^{57}}{P I B_{2016}}\left(\frac{\Delta V A_{2017}^{57}}{V A_{2016}^{57}}\right) 100=0,97\left(\frac{783.326}{814.978 .515}\right) 100 \cong 0,09 \%,
\end{gathered}
$$

Al descontar la inversión en el sector construcción se tiene un impacto neto de COP\$472.918 millones, 0,05\% del crecimiento del PIB de 2017. El Cuadro 2 presenta el impacto económico de esta inversión sobre las 10 principales actividades económicas para 2017, de los proyectos 1, 2 y 3. Este impacto se calcula mediante cada multiplicador individual por sector calculado multiplicado por la inversión realizada. La contribución al crecimiento del PIB nacional del 2017 asociado a la construcción de los tres proyectos fue de 0,27\%:

$$
0,09 \%+0,04 \%+0,14 \%=0,27 \% \text {. }
$$

Ahora, si la contribución total de la inversión en los tres proyectos al crecimiento del PIB del 2017 fue de 0,12\%, entonces el impacto neto o efecto multiplicativo debido a su construcción fue de $0,15 \%$.

\section{CUADRO 2}

Impacto económico neto y bruto por sectores y por inversión de los proyectos 1, 2 y 3, en 2017

\begin{tabular}{|l|r|r|r|}
\hline \multicolumn{1}{|c|}{ Sector económico } & \multicolumn{1}{c|}{ Proyecto 1 } & \multicolumn{1}{c|}{ Proyecto 2 } & \multicolumn{1}{c|}{ Proyecto 3 } \\
\hline $\begin{array}{l}\text { 1. Servicios a las empresas excepto } \\
\text { servicios financieros e inmobiliarios. }\end{array}$ & 91.959 & 40.637 & 146.208 \\
\hline 2. Productos minerales no metálicos. & 48.745 & 21.540 & 77.501 \\
\hline $\begin{array}{l}\text { 3. Productos metalúrgicos básicos } \\
\text { (excepto maquinaria y equipo). }\end{array}$ & 40.983 & 18.111 & 65.161 \\
\hline $\begin{array}{l}\text { 4. Servicios de intermediación } \\
\text { financiera, de seguros y servicios } \\
\text { conexos. }\end{array}$ & 34.609 & 15.294 & 55.026 \\
\hline
\end{tabular}

Fuente: Elaboración propia, con base en información suministrada por DNP y ANI. 


\section{CUADRO 2 (Continuación)}

Impacto económico neto y bruto por sectores y por inversión de los proyectos 1, 2 y 3, en 2017

\begin{tabular}{|c|c|c|c|}
\hline Sector económico & Proyecto 1 & Proyecto 2 & Proyecto 3 \\
\hline & COP\$ millones & COP\$ millones & COP\$ millones \\
\hline $\begin{array}{l}\text { 5. Servicios inmobiliarios y de alquiler } \\
\text { de vivienda. }\end{array}$ & 24.061 & 10.632 & 38.255 \\
\hline $\begin{array}{l}\text { 6. Productos de la refinación del } \\
\text { petróleo; combustible nuclear. }\end{array}$ & 22.486 & 9.937 & 35.751 \\
\hline 7. Servicios de transporte terrestre. & 19.878 & 8.784 & 31.605 \\
\hline 8. Productos de caucho y de plástico. & 17.382 & 7.681 & 27.636 \\
\hline 9. Energía eléctrica. & 16.195 & 7.157 & 25.750 \\
\hline $\begin{array}{l}\text { 10. Servicios de reparación de } \\
\text { automotores, de artículos personales y } \\
\text { domésticos. }\end{array}$ & 14.321 & 6.328 & 22.769 \\
\hline 11. Otros. & 142.299 & 62.882 & 226.245 \\
\hline $\begin{array}{l}\text { Impacto neto. } \\
\text { Inversión. }\end{array}$ & $\begin{array}{l}472.918 \\
310.408\end{array}$ & $\begin{array}{r}208.983 \\
137.170 \\
\end{array}$ & $\begin{array}{l}751.906 \\
493.527\end{array}$ \\
\hline Impacto bruto. & 783.326 & 346.153 & 1.245 .433 \\
\hline PIB 2016 a precios de 2015. & 814.978 .515 & 814.978 .515 & 814.978 .515 \\
\hline $\begin{array}{l}\text { Contribución al crecimiento } 2017 . \\
\text { Crecimiento PIB sin proyecto. }\end{array}$ & $\begin{array}{l}0,09 \% \\
2,41 \%\end{array}$ & $\begin{array}{l}0,04 \% \\
2,46 \%\end{array}$ & $\begin{array}{l}0,14 \% \\
2,36 \%\end{array}$ \\
\hline Crecimiento PIB total estimado 2017. & $2,50 \%$ & $2,50 \%$ & $2,50 \%$ \\
\hline PIB 2017 estimado a precios de 2015. & 835.352 .978 & 835.352 .978 & 835.352 .978 \\
\hline
\end{tabular}

Fuente: Elaboración propia, con base en información suministrada por DNP y ANI.

Si en 2017 el impacto bruto asociado con la construcción del proyecto 1 fue de COP\$783.326 millones y el crecimiento estimado para ese año por las entidades gubernamentales con la construcción del proyecto 1 fue de $2,50 \%$, el PIB nacional se incrementará (pasará en términos de crecimiento) de 2,41\% a 2,50\% como consecuencia de la inversión de la construcción sobre el VA de los cincuenta y siete (57) sectores $\mathrm{VA}_{\mathrm{t}}^{57}$. En síntesis, el aumento de la inversión debido a la construcción del proyecto 1 genera un efecto intersectorial sobre la 
economía nacional valorado en una contribución al crecimiento del PIB del 0,09\%, como se observa en el Cuadro 3.

\section{CUADRO 3}

Impactos anuales sobre el PIB, por inversión, Proyecto 1

(millones de pesos constantes de 2015)

\begin{tabular}{|c|c|c|c|c|c|c|c|c|}
\hline Año & $\begin{array}{c}\text { Inversión } \\
\text { Proyecto 1 }\end{array}$ & $\begin{array}{c}\text { Impacto } \\
\text { Millones }\end{array}$ & $\begin{array}{c}\text { \%PIB } \\
\text { (Neto) }\end{array}$ & $\begin{array}{c}\text { Impacto Bruto } \\
\text { COP\$ } \\
\text { Millones }\end{array}$ & $\begin{array}{c}\text { Crecimiento } \\
\text { PIB } \\
\text { Sin proyecto }\end{array}$ & $\begin{array}{c}\text { Contribución } \\
\% \text { PIB (Bruto) }\end{array}$ & $\begin{array}{c}\text { Estimación } \\
\text { Crecimiento } \\
\text { PIB }\end{array}$ & $\begin{array}{c}\text { PIB } \\
\text { estimado }\end{array}$ \\
\hline 2015 & 15,78 & 24,041 & $0,00 \%$ & 39,821 & $3,04 \%$ & $0,01 \%$ & $3,05 \%$ & 799.312 .000 \\
\hline 2016 & 157,593 & 381,912 & $0,03 \%$ & 397,692 & $1,91 \%$ & $0,05 \%$ & $1,96 \%$ & 814.978 .515 \\
\hline 2017 & 310,408 & 472,918 & $0,05 \%$ & 783,326 & $2,41 \%$ & $0,09 \%$ & $2,50 \%$ & 835.352 .978 \\
\hline 2018 & 677,422 & 1.032 .077 & $0,12 \%$ & 1.709 .499 & $3,30 \%$ & $0,20 \%$ & $3,50 \%$ & 864.590 .332 \\
\hline 2019 & 243,493 & 370,97 & $0,04 \%$ & 614,463 & $4,13 \%$ & $0,07 \%$ & $4,20 \%$ & 900.903 .126 \\
\hline
\end{tabular}

Fuente: Elaboración propia y con base en información suministrada por DNP.

Para estimar el impacto del proyecto en 2015 y 2016, el supuesto base es que la inversión ya se realizó, por lo tanto, el crecimiento del PIB asociado ya está incluido en los cálculos realizados por las entidades oficiales. No obstante, se presentan los cálculos de los rubros respectivos de manera separada para mostrar la contribución que tuvo el proyecto sobre el PIB en estos años. Como se observa en el Cuadro 3, la proyección de las entidades gubernamentales y el crecimiento con la construcción del proyecto 1 son las mismas, lo que refleja la incorporación del impacto de la inversión en el proyecto, en cuanto al crecimiento que estas reportan. Para los siguientes años, 2018 y 2019, se estiman la contribución neta, bruta y demás rubros en forma similar a la realizada para el 2017. En el caso de los proyectos 2 y 3 la metodología es similar a la presentada para el proyecto 1 y se resume en la siguiente sección. 


\section{CUADRO 4}

Impactos anuales totales sobre el PIB nacional (millones de pesos constantes de 2015)

\begin{tabular}{|c|c|c|c|c|c|c|c|}
\hline Año & $\begin{array}{c}\text { Inversión } \\
\text { Proyecto 1 }\end{array}$ & $\begin{array}{c}\text { Inversión } \\
\text { Proyecto 2 }\end{array}$ & $\begin{array}{c}\text { Inversión } \\
\text { Proyecto 3 }\end{array}$ & $\begin{array}{c}\text { Inversión total } \\
\text { Proyecto }\end{array}$ & $\begin{array}{c}\text { Crecimiento } \\
\text { PIB } \\
\text { Sin proyecto }\end{array}$ & $\begin{array}{c}\text { Contribución } \\
\% \text { PIB (Bruto) }\end{array}$ & $\begin{array}{c}\text { Estimación } \\
\text { Crecimiento } \\
\text { PIB }\end{array}$ \\
\hline 2014 & 0 & 0 & 41,69 & 41,69 & $4,38 \%$ & $0,01 \%$ & $4,39 \%$ \\
\hline 2015 & 15,78 & 0 & 131,829 & 147,609 & $3,00 \%$ & $0,05 \%$ & $3,05 \%$ \\
\hline 2016 & 157,593 & 49,729 & 422,608 & 629,93 & $1,76 \%$ & $0,20 \%$ & $1,96 \%$ \\
\hline 2017 & 310,408 & 137,17 & 493,527 & 941,105 & $2,23 \%$ & $0,27 \%$ & $2,50 \%$ \\
\hline 2018 & 677,422 & 181,036 & 72,297 & 930,755 & $3,23 \%$ & $0,27 \%$ & $3,50 \%$ \\
\hline 2019 & 243,493 & 335,646 & 0 & 579,139 & $4,03 \%$ & $0,17 \%$ & $4,20 \%$ \\
\hline 2020 & 0 & 49,509 & 0 & 49,509 & $4,12 \%$ & $0,01 \%$ & $4,13 \%$ \\
\hline
\end{tabular}

Fuente: Elaboración propia y con base en información suministrada por DNP.

El impacto total sobre el PIB nacional asociado a la inversión del corredor vial Santana-Puerto Salgar se estimó a partir de cada una de las inversiones en los proyectos 1,2 y 3 , de forma similar a como se determinó en el ítem anterior para el proyecto 1 .

Para 2017 se espera que la contribución de la inversión total al PIB sea de $0,27 \%$, lo que implica que con la proyección oficial este pasaría, en términos de crecimiento, de $2,23 \%$ a $2,50 \%$, como se muestra en el Cuadro 4 . Es importante nuevamente resaltar que en cada proyecto para los años 2014, 2015 y 2016 se hace el supuesto de que la inversión ya se realizó, por lo tanto, aunque se establecen los cálculos de los rubros respectivos, el crecimiento del PIB según el DANE ya incorpora el impacto de la construcción del proyecto. El Cuadro 4 presenta las proyecciones de las entidades gubernamentales y el crecimiento del PIB como consecuencia de la inversión anual del proyecto total durante la etapa de construcción. 


\section{E. Resultados de la contribución al PIB con multiplicadores Leontief para la etapa de operación}

Al igual que en la etapa de construcción, se presentan impactos en la economía nacional asociados a la puesta en marcha o entrada en operación de las concesiones. Para medirlos durante la etapa de operación se usó la variación porcentual del crecimiento del PIB. Esta variación porcentual es causa del incremento de la demanda de bienes de construcción para el mantenimiento de los proyectos, y se mide a través de los Multiplicadores Leontief que permiten cuantificar el impacto sobre el VA (PIB).

La información para el cálculo de los Multiplicadores Leontief proviene de la Matriz Utilización Desagregada en Productos Nacionales e Importados del DANE; de igual forma se usó la estimación del PIB realizada por entidades gubernamentales para calcular las participaciones respectivas.

El impacto se calcula para los tres proyectos, pero se ilustra para el proyecto 1 . El costo económico asociado al mantenimiento del proyecto 1 es de COP\$317.219 millones de 2015 durante el 2020 y 2024, según lo informa ANI (2015). En el Gráfico 2 se describen los flujos. En este caso, para el logro de los resultados deseables se parte del supuesto del cumplimiento anual del cronograma de mantenimiento del proyecto 1 . También estos resultados están sujetos a la ausencia de impactos negativos en la economía, lo cual se recoge con la proyección del PIB nacional realizada por las entidades gubernamentales.

El efecto económico de estos costos de mantenimiento y operación, que se refleja mediante la anualización de los costos económicos, se examina usando en forma similar los Multiplicadores Leontief. La metodología que se aplica en esta etapa del proyecto es la misma que se usó en la etapa de construcción, pero usando el valor referente a los costos de operación y mantenimiento; por tanto, el multiplicador es igual al de la etapa de construcción. El multiplicador generado por cada $\operatorname{COP} \$ 1,0$ invertido es de 2,52 asociado al mantenimiento del proyecto y en términos netos es de 1,52. En el caso del corto plazo, este multiplicador permite estimar la contribución al crecimiento económico. Por ejemplo, en 2020 el costo de operación realizado en el mantenimiento del proyecto 1 implica un crecimiento del PIB de 0,01\%. Este incremento proviene del mantenimiento y operación inicial de COP $\$ 48.504$ millones, más el impacto neto que genera en la economía, y que se valora en COP\$73.898 millones. Los principales sectores que se ven afectados son los que se presentan en el Cuadro 5. 


\section{GRÁFICO 2 \\ Costos operación del proyecto 1 \\ (millones de pesos constantes de 2015)}

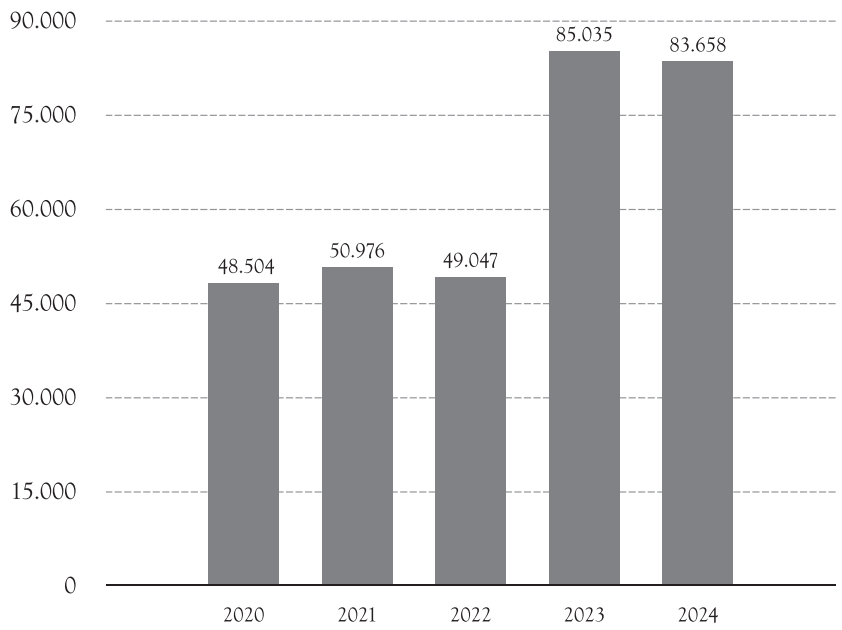

Fuente: Elaboración propia, con base en información suministrada por DNP y ANI.

\section{CUADRO 5}

Impacto discriminado principales sectores por mantenimiento y operación proyecto 1,2 y 3

\begin{tabular}{|l|r|r|r|}
\hline \multicolumn{1}{|c|}{ Sector económico } & \multicolumn{1}{|c|}{$\begin{array}{c}\text { Proyecto 1 } \\
\text { 2020 COP\$ } \\
\text { millones }\end{array}$} & $\begin{array}{c}\text { Proyecto 2 } \\
\text { 2021 COP\$ } \\
\text { millones }\end{array}$ & $\begin{array}{c}\text { Proyecto 3 } \\
\text { 2019 COP\$ } \\
\text { millones }\end{array}$ \\
\hline $\begin{array}{l}\text { 1. Servicios a las empresas excepto servicios } \\
\text { financieros e inmobiliarios. }\end{array}$ & 14.369 & 10.161 & 8.057 \\
\hline 2. Productos minerales no metálicos. & 7.617 & 5.386 & 4.271 \\
\hline $\begin{array}{l}\text { 3. Productos metalúrgicos básicos (excepto } \\
\text { maquinaria y equipo). }\end{array}$ & 6.404 & 4.529 & 3.591 \\
\hline $\begin{array}{l}\text { 4. Servicios de intermediación financiera, de } \\
\text { seguros y servicios conexos. }\end{array}$ & 5.408 & 3.824 & 3.032 \\
\hline $\begin{array}{l}\text { 5. Servicios inmobiliarios y de alquiler de } \\
\text { vivienda. }\end{array}$ & 3.760 & 2.659 & 2.108 \\
\hline
\end{tabular}

Fuente: Elaboración propia, con base en información suministrada por DNP y DANE. 


\section{CUADRO 5 (Continuación)}

Impacto discriminado principales sectores por mantenimiento y operación proyecto 1,2 y 3

\begin{tabular}{|l|r|r|r|}
\hline \multicolumn{1}{|c|}{ Sector económico } & \multicolumn{1}{|c|}{$\begin{array}{c}\text { Proyecto 1 } \\
\text { 2020 COP\$ } \\
\text { millones }\end{array}$} & \multicolumn{1}{c|}{$\begin{array}{c}\text { Proyecto 2 } \\
\text { 2021 COP\$ } \\
\text { millones }\end{array}$} & $\begin{array}{c}\text { Proyecto 3 } \\
\text { 2019 COP\$ } \\
\text { millones }\end{array}$ \\
\hline $\begin{array}{l}\text { 6. Productos de la refinación del petróleo; } \\
\text { combustible nuclear. }\end{array}$ & 3.514 & 2.485 & 1.970 \\
\hline 7. Servicios de transporte terrestre. & 3.106 & 2.196 & 1.742 \\
\hline 8. Productos de caucho y de plástico. & 2.716 & 1.921 & 1.523 \\
\hline 9. Energía eléctrica. & 2.531 & 1.790 & 1.419 \\
\hline $\begin{array}{l}\text { 1. Servicios de reparación de automotores, } \\
\text { de artículos personales y domésticos. }\end{array}$ & 2.238 & 1.582 & 1.255 \\
\hline 11. Otros. & 22.235 & 15.724 & 12.467 \\
\hline $\begin{array}{l}\text { Impacto Neto. } \\
\text { Inversión. }\end{array}$ & 73.898 & 52.256 & 41.433 \\
\hline Impacto Bruto. & 122.402 & 86.555 & 68.628 \\
\hline PIB 2019 estimado a precios del 2015. & 960.200 .025 & 999.952 .306 & 920.084 .348 \\
\hline Contribución al crecimiento 2020. & $0,01 \%$ & $0,009 \%$ & $0,007 \%$ \\
\hline $\begin{array}{l}\text { Crecimiento PIB bajo construcción } \\
\text { proyecto. }\end{array}$ & $4,13 \%$ & $3,87 \%$ & $4,24 \%$ \\
\hline
\end{tabular}

Fuente: Elaboración propia, con base en información suministrada por DNP y DANE.

Al igual que en el corto plazo, el Cuadro 6 presenta el impacto sobre el PIB para los años 2020-2024 para el Proyecto 1, similar a como se calculó para la etapa de inversión. Es decir, si el impacto bruto debido a la operación y mantenimiento de una etapa del proyecto en el año 2020 es de COP\$122.402 millones, su contribución al crecimiento del PIB es del 0,01\%. ${ }^{6}$ Para los siguientes años, 2021 a 2024, se estima la contribución neta y bruta y demás rubros en forma similar a la realizada para el 2020. Es de resaltar que los resultados para los proyectos 2 y 3 se calculan de forma similar al proyecto 1 y los resultados se resumen en la siguiente sección.

\footnotetext{
${ }^{6}$ Se resalta que el crecimiento del PIB estimado para el 2020 por las entidades gubernamentales incorpora este impacto; por tanto, se espera que el PIB se incremente en un 4,13\%, es decir esta proyección incorpora dicho crecimiento como consecuencia del impacto de los costos de operación en el mantenimiento vial sobre el $V A_{t}^{57}$
} 

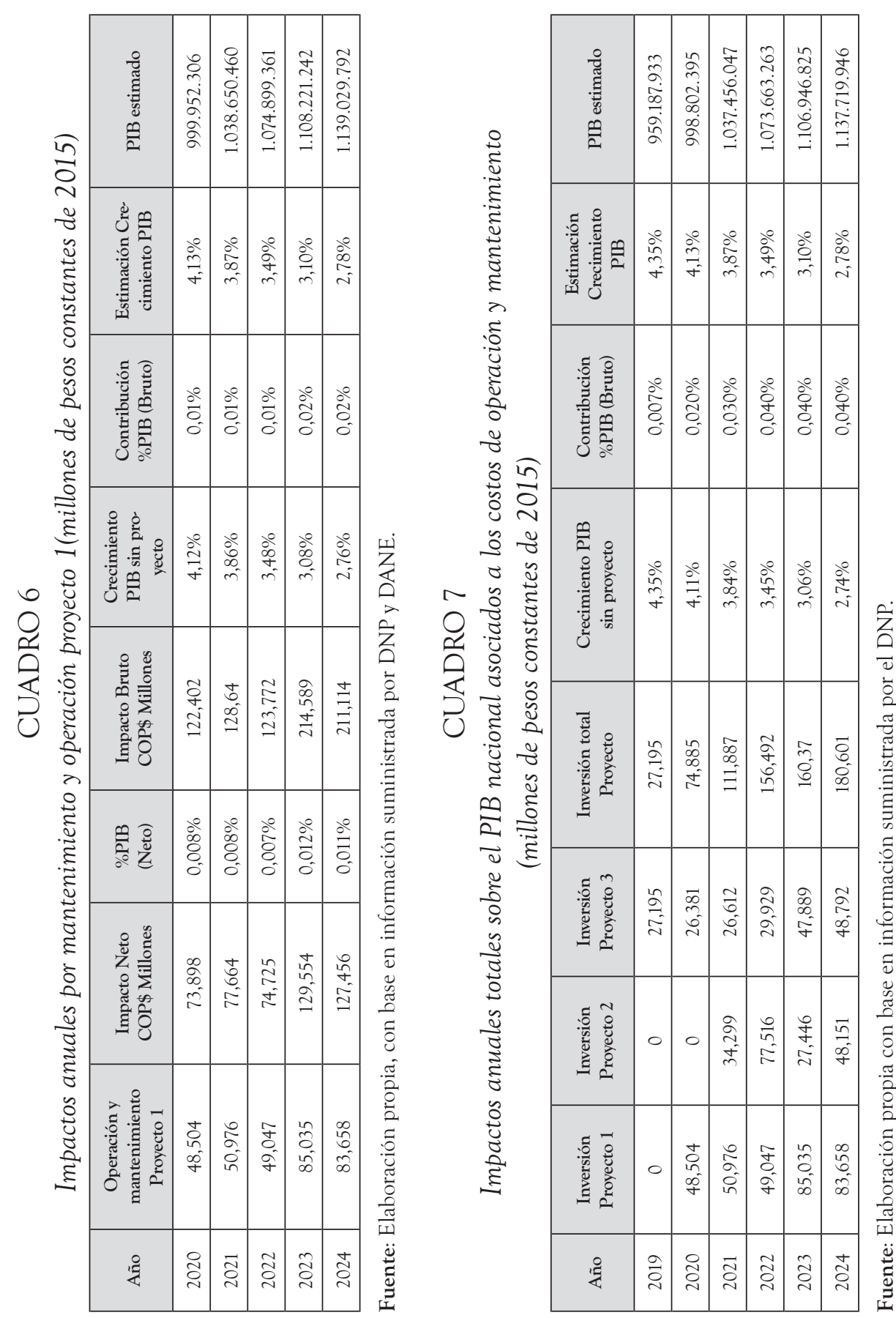
El impacto total sobre el PIB nacional asociado a los costos en la etapa de operación y mantenimiento de todo el proyecto Santana-Puerto Salgar se estimó a partir de la inversión (costos de operación adicionales) en los proyectos 1, 2 y 3. Para 2019 los costos realizados son solo para el proyecto 3, por lo cual el impacto bruto sobre el PIB fue marginal, arrojando así un valor muy bajo, aproximadamente de $0,007 \%$. Para 2020, y en adelante, los costos de operación y mantenimiento son mayores, generando un impacto bruto de 0,02\%. En 2021 y 2022, dado que la inversión en la etapa de operación aumenta, también lo hace el impacto bruto sobre el PIB en 0,03\% y 0,04\%. El Cuadro 7 muestra los resultados totales.

A partir de la información suministrada en los Cuadros 4 y 7 , que resumen las consecuencias de la inversión y los costos de operación y mantenimiento, se concluye que el impacto sobre el crecimiento del PIB asociado en las dos etapas (inversión-operación y mantenimiento) para 2019 y 2020, es del 0,18\% y 0,03\% respectivamente.

\section{IMPACTO SOCIAL CONCESIONES VIALES 4G: INDICADORES DE POBREZA}

El impacto social asociado a la construcción y puesta en operación de las vías $4 \mathrm{G}$ se mide mediante indicadores relacionados con la pobreza, acceso a oportunidades y reducción en tiempos de traslado entre zonas rurales y urbanas. Este último indicador es fundamental en la estimación del incremento del ingreso de la población beneficiada por el proyecto. Mediante un modelo de datos longitudinal que incorpora la reducción en tiempos de traslado y variables de control, permite establecer el incremento del ingreso asociado a la realización del proyecto. Esta metodología se presenta en la siguiente sección. Este documento estima este efecto a partir de la variación en los indicadores de pobreza, específicamente por medio de la variación del Índice de Pobreza Monetaria, al comparar la situación sin y con proyecto -personas que salen de la pobreza monetaria debido a la construcción y puesta en operación de los corredores viales $4 \mathrm{G}$ y el Índice de la Pobreza Multidimensional que permite estimar cómo la construcción y puesta en operación de los corredores viales está asociado a que la población salga de la pobreza multidimensional. Se toma como caso de estudio el corredor Santana-Puerto Salgar. 


\section{A. Aspectos metodológicos del cálculo de la pobreza monetaria y multidimensional ${ }^{7}$}

El cálculo del Índice de Pobreza Monetaria es un indicador que parte de la información de la Gran Encuesta Integrada de Hogares, en el caso particular de 2015, las líneas de pobreza se presentan en relación con el dinero per cápita mínimo mensual requerido para la compra una canasta mínima de consumo (alimentos, bienes y servicios), y a este último valor se le denomina la línea de la pobreza (DANE, 2017).

Para el cálculo se usó el módulo de Medición de Pobreza Monetaria y Desigualdad 2015, y la Gran Encuesta Integrada de Hogares (GEIH) recopilado por el DANE para 2015 con el fin de vincular la actividad económica de las personas incluidas en la GEIH y su estado de pobreza monetaria registrada en la Medición de Pobreza Monetaria y Desigualdad. Además, se aplicó el Factor de Expansión del $\operatorname{Hogar}^{8}$ con el propósito de estimar si la persona es pobre, según las líneas de pobreza del DANE.

Según las fuentes de información anteriores se construyó una base de datos para cada fase del proyecto. Se tomaron los ingresos de las personas que se desempeñan laboralmente en los sectores económicos de construcción, transporte, comercio y hoteles, y, además, se filtraron solo aquellas personas que tenían como residencia los departamentos de influencia directa: Caldas, Cauca, Cundinamarca, Huila y Tolima. La ecuación 2 presenta la rutina para ampliar la información a términos poblacionales, en la que se parte de cada individuo que cumple con los anteriores requisitos y se le aplica el factor de expansión.

$$
P R_{i}=(P)\left(F E X_{i}\right)
$$

Donde:

$P R_{i}:$ Población (número de personas) que representa el individuo $i$.

$P_{i}$ : Personas que componen el hogar del individuo $i$.

FEX $_{i}$ : Factor de expansión del individuo $i$.

\footnotetext{
${ }^{7}$ Esta sección recibió el apoyo de Jorge Armando Rueda, investigador CEDE de la Facultad de Economía de la Universidad de los Andes, a quien le agradecemos su colaboración.

${ }^{8}$ El factor de expansión es un valor que multiplica a cada uno de los elementos seleccionados en la muestra para valorar el parámetro en el universo; este factor depende y se construye a partir del método de selección utilizado por el DANE (2005).
} 
Por medio del ingreso per cápita calculado con la GEIH para el individuo $i$, se estima si es pobre con la información de su línea de pobreza monetaria, y se aplica el resultado a la población que representa $P R_{i}$ usando el factor de expansión del individuo $i$. A modo de ejemplo, se presentan dos casos típicos en el Cuadro 8 para 2015.

\section{CUADRO 8}

\section{Pobreza Monetaria, casos típicos en 2015}

\begin{tabular}{|c|c|c|c|c|c|c|c|c|}
\hline $\begin{array}{c}\text { Indivi- } \\
\text { duo id }\end{array}$ & $\begin{array}{c}\text { Departa- } \\
\text { mento }\end{array}$ & $\begin{array}{c}\text { Rama de } \\
\text { trabajo }\end{array}$ & $\begin{array}{c}\text { Ingresos } \\
\text { per cápita } \\
\text { COP\$ }\end{array}$ & $\begin{array}{c}\text { Línea } \\
\text { de } \\
\text { pobreza }\end{array}$ & $\begin{array}{c}\text { Pobre } \\
\text { Mone- } \\
\text { tario }\end{array}$ & $\begin{array}{c}\text { Factor de } \\
\text { expansión } \\
\text { departamen- } \\
\text { tal }\end{array}$ & $\begin{array}{c}\text { Número de } \\
\text { personas } \\
\text { hogar }\end{array}$ & $\begin{array}{c}(1) *(2) \\
\text { Representa- } \\
\text { ción } \\
\text { poblacional }\end{array}$ \\
\hline 3639564 & Caldas & $\begin{array}{c}\text { Construcción } \\
\text { y Hoteles }\end{array}$ & 1.592 .314 & 234,346 & No & 16,54 & 5 & 82,7 \\
\hline 3639541 & Tolima & Comercio & 207,5 & 245,535 & Si & 95,15 & 2 & 190,3 \\
\hline
\end{tabular}

Fuente: Elaboración propia con base en información suministrada por el DANE.

Siguiendo los aspectos metodológicos, para el cálculo de la población pobre durante la etapa de construcción se tuvo en cuenta la línea de pobreza de 2015 ajustada por la inflación, y el ingreso per cápita ajustado por el incremento del salario mínimo más el impacto sobre el ingreso asociado con la construcción del corredor en los sectores económicos afectados. El Anexo B presenta estos resultados. Con estos elementos se estimó que la pobreza en los departamentos de influencia en 2016 fue de 2.463 .845 personas. Para establecer la población pobre durante la etapa de operación se usó una metodología similar, pero teniendo en cuenta las actividades económicas de los sectores agropecuario, de minas e industria manufacturera.

Para calcular la variación de la Pobreza Multidimensional Ajustada se usó como fuente principal nuevamente la GEIH y la metodología señalada en el Conpes Social 150 (DNP, 2017). Esta metodología contempla 5 bloques y 15 variables, como lo hace el Índice de Pobreza Multidimensional. ${ }^{9}$ Los bloques que contiene este índice son: educación, niñez y juventud, salud, trabajo, servicios públicos y condiciones de vivienda. Las variables que contienen cada bloque

\footnotetext{
${ }^{9}$ Se usó la Gran Encuesta Integrada de Hogares 2015 en lugar de la Encuesta Nacional de Calidad de Vida dado que esta última no permite calcular el indicador a nivel departamental.
} 
y la ponderación respectiva se presentan en el Cuadro 9. A estas variables se les aplicó una ponderación mayor que cero cuando cumplen la definición del Cuadro 9; si suman 33,33\% o más, el hogar y las personas que lo componen se consideran pobres.

\section{CUADRO 9}

Bloques y variables del Índice de Pobreza Multidimensional*

\begin{tabular}{|c|c|c|c|c|}
\hline $\begin{array}{l}\text { 1. Educación } \\
(0,2)\end{array}$ & $\begin{array}{l}\text { 2. Niñez y Juventud } \\
(0,2)\end{array}$ & 3. Salud $(0,2)$ & 4. Trabajo $(0,2)$ & 5. Vivienda $(0,2)$ \\
\hline $\begin{array}{c}\cdot \text { Bajo logro } \\
\text { educativo } \\
(0,1)\end{array}$ & $\begin{array}{l}\text { - Inasistencia } \\
\text { escolar }(0,05) \text {, }\end{array}$ & $\begin{array}{c}\text { - Desempleo de } \\
\text { larga duración } \\
\qquad(0,1)\end{array}$ & $\begin{array}{c}\text {-Sin asegura- } \\
\text { miento en salud } \\
(0,1),\end{array}$ & $\begin{array}{c}\cdot \text { Sin acceso a } \\
\text { fuente de agua } \\
\text { mejorada }(0,04) \text {, }\end{array}$ \\
\hline \multirow[t]{4}{*}{$\begin{array}{c}\text { - Analfabetis- } \\
\text { mo }(0,1) \text {. }\end{array}$} & $\begin{array}{c}\text { - Rezago escolar } \\
\qquad(0,05)\end{array}$ & $\begin{array}{c}\text {-Empleo infor- } \\
\text { mal }(0,1)\end{array}$ & $\begin{array}{c}\text { - Barreras de } \\
\text { acceso a servicio } \\
\text { de salud }(0,1) \text {. }\end{array}$ & $\begin{array}{l}\text { - Inadecuada } \\
\text { eliminación de } \\
\text { excretas }(0, z 04) \text {, }\end{array}$ \\
\hline & $\begin{array}{c}\bullet \text { Barreras de } \\
\text { acceso a servicios } \\
\text { para el cuidado de } \\
\text { la primera infancia } \\
(0,05),\end{array}$ & & & $\begin{array}{c}\text { - Pisos inadecua- } \\
\text { dos }(0,04)\end{array}$ \\
\hline & $\begin{array}{l}\text { - Trabajo infantil } \\
\qquad(0,05) .\end{array}$ & & & $\begin{array}{l}\text { - Paredes exterio- } \\
\text { res inadecuadas } \\
(0,04)\end{array}$ \\
\hline & & & & $\begin{array}{l}\text { - Hacinamiento } \\
\text { crítico }(0,04) .\end{array}$ \\
\hline
\end{tabular}

Nota: Entre paréntesis las ponderaciones para cálculo del hogar pobre.

Fuente: Elaboración propia, a partir de información del Conpes Social 150.

\section{B. Información estudio de caso}

La información básica para calcular el Índice de Pobreza Monetaria y el Índice de Pobreza Multidimensional Ajustado es la Gran Encuesta Integrada de Hogares 2015 del DANE, específicamente los módulos Desocupados, Fuerza de Trabajo, Inactivos, Ocupados, Personas y Vivienda. Los departamentos de influencia directa fueron Caldas, Cauca, Cundinamarca, Huila y Tolima. Los 
sectores económicos examinados fueron construcción, transporte, comercio y hoteles para la etapa de construcción, y agropecuario, de minas y la industria manufacturera para la etapa de operación.

\section{Resultados en reducción de pobreza monetaria}

Para estimar la reducción de la pobreza monetaria se debe precisar que el aumento en el ingreso laboral ${ }^{10}$ asociado a la construcción del corredor se presenta de manera heterogénea entre los trabajadores. Por un lado, existen algunos sectores económicos que se benefician directamente de la etapa de construcción y su posterior etapa de operación y mantenimiento (i.e. construcción, transporte, comercio y hoteles), mientras que, por otro lado, existen sectores que se benefician cuando entra en operación el trayecto (i.e. sector agropecuario, de minas y la industria manufacturera).

De esta manera y teniendo en cuenta el incremento en el ingreso asociado a las etapas de construcción, operación y mantenimiento, se presentan los incrementos en el ingreso per cápita que se derivan de los resultados de la estimación del modelo gravitacional que permite estimar el incremento en los ingresos asociado a la disminución en las distancias generadas por la construcción del proyecto (Cuadro 10). El Anexo C presenta la metodología y resultados del incremento del ingreso per cápita usando este modelo.

Considerando el incremento del ingreso laboral, y con el objetivo de examinar la variación del número de personas pobres en términos monetarios asociado a la construcción, operación y mantenimiento, entre 2015 y 2024, del tramo Santana-Puerto Salgar, se deben tener en cuenta varios detalles y supuestos sobre las variables. En primer lugar, la tasa de crecimiento de salario se asumió en 4,59\% (crecimiento nominal promedio 2011 a 2015) y constante para el periodo analizado, como se expone en el Cuadro B1 del Anexo B, y está definida como el promedio según la variación de los últimos cinco años. Segundo, se supone una línea de pobreza con un crecimiento anual según la variación del Índice de Precios al Consumidor (IPC), fin de periodo (DNP y DANE 2017; Cuadro B2 del Anexo B). Finalmente, se supone que la población departamental está definida según las proyecciones de población realizadas por el DANE a partir del Censo de Población y Vivienda de 2005 para el periodo 2015-2020. Para los años restantes (2021-2024) se consideró que la población

${ }^{10} \mathrm{El}$ incremento del ingreso laboral se deriva del efecto multiplicativo económico directo que se genera en los departamentos de influencia de la concesión, según se expone en el Anexo B. 
se incrementa según la tasa promedio del periodo 2016-2017 (Cuadro B3 del Anexo B).

\section{CUADRO 10}

Incremento anual en el ingreso laboral

\begin{tabular}{|c|c|c|c|c|c|c|c|c|c|c|}
\hline \multicolumn{1}{|c|}{ Etapa } & \multicolumn{5}{|c|}{ Construcción } & \multicolumn{5}{c|}{ Operación y mantenimiento } \\
\hline \multicolumn{1}{|c|}{ Año } & 2015 & 2016 & 2017 & 2018 & 2019 & 2020 & 2021 & 2022 & 2023 & 2024 \\
\hline $\begin{array}{l}\text { Incremento adicional en } \\
\text { el ingreso laboral - Sectores } \\
\text { construcción, transporte, } \\
\text { comercio y hotelería. }\end{array}$ & $0,00 \%$ & $0,00 \%$ & $0,20 \%$ & $0,50 \%$ & $1,00 \%$ & $1,50 \%$ & $2,00 \%$ & $2,50 \%$ & $3,00 \%$ & $3,50 \%$ \\
\hline $\begin{array}{l}\text { Incremento adicional en } \\
\text { el ingreso laboral - Sectores } \\
\text { agropecuario, minas e } \\
\text { industria manufacturera. }\end{array}$ & $0,00 \%$ & $0,00 \%$ & $0,00 \%$ & $0,00 \%$ & $0,00 \%$ & $0,50 \%$ & $1,00 \%$ & $1,50 \%$ & $2,00 \%$ & $2,50 \%$ \\
\hline
\end{tabular}

Fuente: Elaboración propia.

Cabe resaltar que no todos los sectores económicos se benefician de manera similar por el incremento salarial, de manera que se requiere conocer la rama económica en la que trabaja la persona ocupada y su ingreso laboral. Ilustrativamente, en el Cuadro 10 se muestra que, si el trabajador pertenece al sector de construcción, transporte, comercio y hotelería, ${ }^{11}$ para 2017 se simula el crecimiento del ingreso laboral en 0,2\% (resultado modelo gravitacional, Anexo B) adicional al crecimiento del salario mínimo que se estableció en 4,59\% para obtener el nuevo ingreso. Luego se incrementa el valor en 0,5\%, adicional al 4,59\% para calcular el ingreso de 2018, y así sucesivamente hasta el 2024..$^{12}$

En cambio, si los trabajadores pertenecen al sector agropecuario, de minas o de industria manufacturera, mantienen constante su ingreso laboral durante la fase de construcción, y experimentarán el incremento durante la fase de operación y mantenimiento del tramo. Paralelamente, se estimaron las líneas de

\footnotetext{
${ }^{11}$ Se asumió que todos los trabajadores de estos sectores incrementaron su ingreso laboral de manera proporcional.

${ }^{12}$ Cada uno de los años se ajustó según el incremento en los salarios y la tasa de crecimiento del salario mínimo.
} 
la pobreza ${ }^{13}$ según el incremento en el IPC (el cuadro B4 del Anexo B presenta ilustraciones del cambio en los valores de la línea de la pobreza).

Una vez estimado el incremento del ingreso en cada uno de los años para los dos grupos de empleados (sector de construcción, transporte, comercio, hotelería y sector agropecuario, minas e industria manufacturera) en la dos etapas (construcción y operación-mantenimiento), se adicionan al ingreso sin proyecto para cada hogar, con el propósito de obtener el ingreso per cápita con proyecto..$^{14}$ A partir de estos cómputos se determina si los recursos económicos para cada miembro del hogar son suficientes para garantizar la canasta mínima de consumo de bienes y servicios, es decir, si están por encima o por debajo de la línea de pobreza.

Finalmente, se aplicaron dos procedimientos técnicos para obtener el número de personas pobres asociados a la construcción y puesta en operación de la concesión. El primero, mantener inicialmente constante la población, y a partir de las variaciones del ingreso per cápita y del valor de la línea de la pobreza, definir el número de personas pobres que no logran adquirir la canasta mínima de consumo, según se puede observar en el Cuadro B5 del Anexo B. El segundo consiste de tomar la tasa de reducción de la pobreza $(\gamma)$, según las estimaciones anteriores, y ajustarla según la tasa de crecimiento poblacional $(g)$ del DANE, como se aprecia en el Cuadro B3 del Anexo B. Según estas consideraciones, es posible definir la población pobre ajustada por el crecimiento poblacional a partir de la ecuación (3), en la que se indica que la población pobre en t es igual a la población del período anterior ajustada por la tasa de crecimiento poblacional y la tasa de pobreza.

$$
\text { Población pobre }{ }_{t}=\text { Población pobre } e_{t-1} \times\left(1+g_{t}\right) \times\left(1+\gamma_{t}\right)
$$

El Cuadro 11 presenta la población total, la población pobre y la incidencia de pobreza monetaria según cada fase del proyecto de los departamentos de Caldas, Cauca, Cundinamarca, Huila y Tolima. Se observa que, según las proyecciones, el número de personas pobres disminuiría en 544.161 y el índice pasaría de 32,1\% en 2016 a 23,2\% en 2024. Específicamente, en la fase de construcción el número de personas que dejarían de ser considerados pobres

\footnotetext{
${ }^{13}$ Se debe mencionar que la línea de la pobreza no se asumió similar para el total de la población, depende del sitio de residencia de la persona. De esta manera, el valor es diferente para un habitante urbano de Neiva (Huila) que para un residente de la zona rural de Coyaima (Tolima).

${ }^{14}$ Nótese que de estos ingresos depende del número de personas pertenecientes al hogar (se excluye a rentistas y empleados domésticos según la metodología del cálculo de pobreza monetaria), por ende, es necesario tener en cuenta el número promedio del hogar para obtener el de cada miembro.
} 
en términos monetarios es de 81.053 , y los años 2019 y 2020 corresponden a los de mayor reducción, asociado a la adición de la población beneficiaria del proyecto, con un valor de 222.095 personas que salen de la pobreza monetaria (reducción de la incidencia al pasar de 30,1\% a 27,1\%).

\section{CUADRO 11}

Población pobre e incidencia de pobreza monetaria según fase, 2016-2024 (Población beneficiada por la concesión Santana-Puerto Salgar)

\begin{tabular}{|c|c|c|c|c|}
\hline Fase & Año & Población & $\begin{array}{c}\text { Población } \\
\text { pobre }\end{array}$ & $\begin{array}{c}\text { Incidencia de } \\
\text { pobreza }\end{array}$ \\
\hline \multirow{4}{*}{ Construcción } & 2016 & 7.684 .227 & 2.463 .845 & $32,1 \%$ \\
\cline { 2 - 5 } & 2017 & 7.757 .917 & 2.463 .545 & $31,8 \%$ \\
\cline { 2 - 5 } & 2018 & 7.831 .065 & 2.416 .876 & $30,9 \%$ \\
\cline { 2 - 5 } & 2019 & 7.903 .310 & 2.382 .792 & $30,1 \%$ \\
\hline \multirow{5}{*}{ Operación } & 2020 & 7.974 .522 & 2.160 .697 & $27,1 \%$ \\
\cline { 2 - 5 } & 2021 & 8.049 .331 & 2.107 .480 & $26,2 \%$ \\
\cline { 2 - 5 } & 2022 & 8.125 .058 & 2.061 .780 & $25,4 \%$ \\
\cline { 2 - 5 } & 2023 & 8.201 .716 & 1.989 .224 & $24,3 \%$ \\
\cline { 2 - 5 } & 2024 & 8.279 .316 & 1.919 .684 & $23,2 \%$ \\
\hline
\end{tabular}

Fuente: Elaboración propia a partir de GEIH (2015), DNP (2017) y DANE (2017).

Se debe mencionar que el comportamiento de la reducción del número de personas pobres es heterogéneo para los departamentos analizados. En particular, el comportamiento depende de la ocupación de las personas, y del ingreso laboral recibido por los trabajadores. Los departamentos que presentan un mayor impacto en reducción de pobreza monetaria fueron, por un lado, Cauca, que gracias al impacto en el salario recibido por los trabajadores redujo en $11,3 \%$ este indicador (es decir, 120.413 personas dejaron de ser pobres para los años analizados); por otro lado, el porcentaje de personas pobres en el Huila es del 44,1\%, 515.748 personas en 2016, y para 2024 se espera que se reduzca a $34 \%$, lo que representa una disminución de 79.022 personas en condición de pobreza monetaria. 


\section{Reducción de la pobreza multidimensional ajustada}

El segundo efecto esperado de las fases de construcción, operación y mantenimiento del tramo Santana-Puerto Salgar, es el mejoramiento de la calidad de vida de la población que se ubica a lo largo del trazado, el cual es estimado a partir del Índice de Pobreza Multidimensional Ajustado (IPM-A). Cabe resaltar que este indicador tiene el objetivo de medir las condiciones de vida por medio de información acerca de educación, salud, trabajo, cuidado de primera infancia y condiciones de vivienda, de acuerdo con lo registrado en el Cuadro 9.

Para calcular el impacto en el mejoramiento de la calidad de vida sobre la población beneficiada se usó nuevamente la GEIH de 2015, que garantiza la representatividad a nivel departamental y se ajusta con lo propuesto por DNP $(2017)^{15}$ que considera cinco dimensiones: (1) condiciones educativas del hogar, que se miden a partir de los logros educativos y el nivel de analfabetismo; (2) condiciones de la niñez y la juventud, a partir de inasistencia escolar, rezago escolar, barrera de acceso, cuidado a primera infancia y trabajo infantil; (3) trabajo, mediante el desempleo de larga duración y el empleo informal; (4) salud, analizada a partir del aseguramiento en salud y las barreras de acceso a servicios de salud; y (5) la disponibilidad de servicios públicos domiciliarios y condiciones de la vivienda, mediante el acceso a fuentes de agua mejorada, inadecuadas eliminación de excretas, pisos y paredes exteriores inadecuados y hacinamiento crítico.

De manera similar al Índice de Pobreza Multidimensional (IPM), cada una de las dimensiones del IPM-A tiene un peso del 20\% (0,2), el cual se divide de manera equitativa dependiendo de la cantidad de variables pertenecientes a cada dimensión. A partir de esta información se determina que una persona es pobre en términos multidimensionales si las privaciones son superiores al $33,33 \%$. En particular, se considera que, si un hogar es pobre, cada uno de sus miembros es considerado pobre.

Teniendo en cuenta lo anterior, y con el objetivo de estimar la reducción en pobreza multidimensional asociada con el trayecto Santana-Puerto Salgar, se buscan las personas que, a partir del incremento en el ingreso laboral, pueden mejorar sus condiciones de vida. Para estimar este número se calcula el porcentaje de personas que son consideradas como pobres monetarios y multidimensionales de manera simultánea. Cabe resaltar que se restringe el análisis a este grupo por dos consideraciones. Primero, aquellas personas que

\footnotetext{
${ }^{15}$ Con la sola encuesta no es posible estadísticamente calcular el IPM definido en el Conpes Social 150, por eso se requiere los ajustes propuestos por DNP (2017).
} 
no son pobres monetarios, pero sí multidimensionales, a pesar de que disponen de un ingreso per cápita superior a la línea de pobreza, no evidencian mejoría en sus condiciones de vida. Segundo, las personas que siendo pobres monetarios no son considerados pobres multidimensionales, se espera que un incremento en el ingreso no les varíe el indicador de calidad de vida.

El Cuadro 12 muestra el número de personas pobres bajo las dos categorías (monetario y multidimensional) en 2015, para Caldas, Cauca, Cundinamarca, Huila y Tolima. A partir de esta información se halló que 4.360 .597 (57,2\%) personas no son pobres según ninguna categoría; mientras que 1.039.266 $(13,6 \%)$ personas presentan carencias tanto en la generación de ingresos como en las condiciones de vida.

\section{CUADRO 12}

Población en condición de pobreza monetaria y/o multidimensional en 2015 (Población beneficiada por la concesión Santana-Puerto Salgar)

\begin{tabular}{|c|c|c|c|}
\cline { 3 - 3 } \multicolumn{2}{c|}{} & \multicolumn{2}{c|}{ Pobre multidimensional } \\
\cline { 3 - 4 } \multicolumn{2}{c|}{} & No & Sí \\
\hline \multirow{2}{*}{ Pobre monetario } & No & 4.360 .597 & 844,744 \\
\cline { 2 - 4 } & Sí & 1.382 .190 & 1.039 .266 \\
\hline
\end{tabular}

Fuente: Elaboración propia a partir de GEIH (2015).

Se espera que el aumento en el ingreso laboral se convierta en mejores condiciones y calidad de vida de los hogares. Con el ánimo de reforzar este vínculo, se estimó una relación entre los indicadores de pobreza monetaria y multidimensional a nivel departamental y para el total de los cinco departamentos (Cuadro C2 del Anexo C). Se encontró que por cada pobre monetario hay 0,778 pobres multidimensionales en $2015 .{ }^{16}$

Teniendo en cuenta lo anterior, el impacto en la reducción de pobreza multidimensional se puede estimar como 0,778 veces la tasa de reducción anual de la incidencia de pobreza monetaria. En particular se propone que el análisis se centre en las personas pobres por ingreso monetario y multidimensional

\footnotetext{
${ }^{16}$ Este 0,778 se calculó a partir de la razón entre el número de pobres multidimensionales sobre el número de pobres monetarios para el total de los departamentos del estudio, según el Cuadro 12, es decir $\frac{1.884 .010}{2.421 .456}=0,778$.
} 
de manera simultánea. La explicación tiene como fundamento que un incremento en la remuneración al trabajo logre mejorar su calidad y condición de vida, todo con el objeto de abandonar la condición de pobres en términos multidimensionales.

De esta forma para definir con mayor aproximación a la población beneficiaria del tramo y teniendo en cuenta las diferencias territoriales ya evidenciadas, se requiere conocer los grados de pobreza a nivel de cada uno de los departamentos (Cuadro 13). Se observa que el departamento que cuenta con la mayor proporción de habitantes en condición de pobreza monetaria y multidimensional es Cauca (26,76\%), seguido de Tolima (16\%). En contraste, Cundinamarca es el de menor incidencia en ambos indicadores, con el 7,02\% de su población, muy similar al departamento de Caldas, con el 8,43\%.

En síntesis, el Cuadro 14 presenta el conjunto de la población en condición de pobreza (definida con ambos métodos) y su porcentaje. Se estimó que para 2016 el número de personas que no genera los recursos mínimos para consumir la canasta de bienes y servicios es de 956.033 (12,44\%); y se espera que al finalizar el proyecto disminuya a 845.797 (10,22\% de la población). Nótese que en este cuadro se tiene en cuenta la población pobre monetaria y multidimensional ajustada por la tasa de crecimiento de la población y por la tasa de crecimiento de los pobres monetarios, usando la razón $\frac{\text { Pobres Multidimensionales }}{\text { Pobres Monetarios }}$ que para el estudio de caso es de 0,778 . 


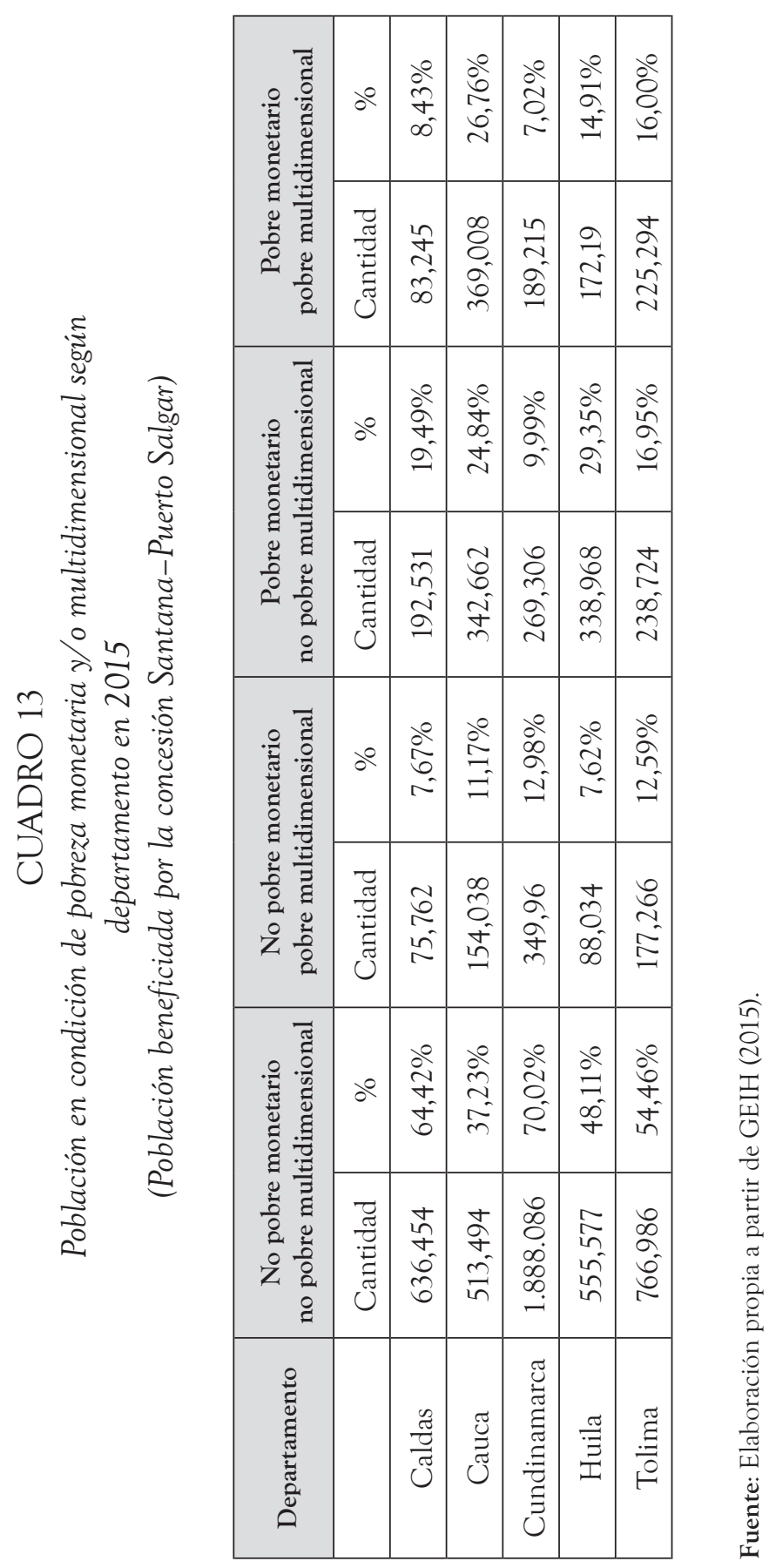




\section{CUADRO 14}

Incidencia de población pobre monetaria y multidimensional, 2015

(Población beneficiada por la concesión Santana-Puerto Salgar)

\begin{tabular}{|c|c|c|c|c|}
\hline \multirow{4}{*}{ Fase } & Año & Población & $\begin{array}{c}\text { Población pobre monetario y } \\
\text { multidimensional }\end{array}$ & Porcentaje \\
\hline \multirow{4}{*}{ Construcción } & 2016 & 7.684 .227 & 956,033 & $12,44 \%$ \\
\cline { 2 - 5 } & 2017 & 7.757 .917 & 964,57 & $12,43 \%$ \\
\cline { 2 - 5 } & 2018 & 7.831 .065 & 959,158 & $12,25 \%$ \\
\cline { 2 - 6 } & 2019 & 7.903 .310 & 956,665 & $12,10 \%$ \\
\hline \multirow{7}{*}{ Operación } & 2020 & 7.974 .522 & 893,724 & $11,21 \%$ \\
\cline { 2 - 5 } & 2021 & 8.049 .331 & 884,49 & $10,99 \%$ \\
\cline { 2 - 5 } & 2022 & 8.125 .058 & 877,372 & $10,99 \%$ \\
\cline { 2 - 5 } & 2023 & 8.201 .716 & 861,675 & $10,51 \%$ \\
\cline { 2 - 5 } & 2024 & 8.279 .316 & 845,797 & $10,22 \%$ \\
\hline
\end{tabular}

Fuente: Elaboración propia a partir de GEIH (2015).

Adicionalmente se destaca que los departamentos que logran la mayor reducción de personas pobres en la etapa de construcción, por el incremento en el ingreso fueron Tolima con 8.173 personas $(0,69 \%)$ y Caldas con 4.158 personas $(0,46 \%)$. Conjuntamente, en sus etapa de operación y mantenimiento disminuyeron $46.043(3,52 \%)$ y $12.672(1,37 \%)$ personas respectivamente.

\section{CONCLUSIONES}

Este documento presentó la metodología de Multiplicadores Leontief para cuantificar el impacto económico que representan las concesiones 4G. Esta metodología parte de analizar un choque sobre la demanda a través de la inversión realizada para la construcción, mantenimiento y puesta en operación de las concesiones. Este impacto genera dos efectos, uno directo y otro indirecto conocido como efecto multiplicativo. El método fue aplicado al corredor SantanaPuerto Salgar, obra cuya construcción se proyectó para durar entre 2014 y 2024. Los principales sectores económicos beneficiados en términos de crecimiento 
son: Servicios a las Empresas -excepto Servicios Financieros e Inmobiliarios, Productos Minerales no Metálicos, Servicios de Transporte Terrestre, Productos de Caucho y de Plástico y Servicios de Reparación de Automotores, de Artículos Personales y Domésticos.

A través del efecto multiplicador se calculó que cada COP $\$ 1,0$ invertido en la concesión Santana-Puerto Salgar se traducirá en COP $\$ 2,52$ en términos de valor bruto de la producción, mientras en términos netos el impacto será de COP\$1,52. Para el caso de la concesión Santana-Puerto Salgar la inversión inicial durante la etapa de construcción para el año 2019 es de COP\$579.139 millones de 2015, que genera un impacto bruto sobre el VA de la nación valorado en COP $\$ 1.461 .478$ millones de 2015, es decir, se multiplica la inversión inicial en 2,52. Si se contemplan estos resultados en términos porcentuales y anuales, durante la etapa de construcción la contribución de este proyecto al PIB de Colombia para el año 2018 es de 0,27\% y para el año 2019 es de 0,17\%. Durante la etapa de operación y mantenimiento los costos adicionales generan un efecto multiplicador, originado en el encadenamiento de 2,52 en términos del valor bruto de la producción. Dicho efecto es idéntico al de la etapa de construcción porque no contempla el modo de ejecución de la inversión, sino el impacto sobre el PIB tanto sectorial como total y sobre la demanda (aumento de la inversión en el sector infraestructura). La contribución al crecimiento del PIB de Colombia durante el periodo de operación y mantenimiento de la concesión Santana-Puerto Salgar es de 0,020\% para el año 2020, 0,030\% para 2021 y 0,040\% anual durante los años 2022 a 2024.

La metodología para medir el impacto social partió de la definición, ajuste y variación del Índice de Pobreza Monetaria y del Índice de Pobreza Multidimensional Ajustado asociado a la construcción y puesta en operación de las concesiones. La reducción de personas pobres medidas por el indicador de pobreza monetaria se cuantificó en 544.161 personas para el periodo 2016 a 2024, es decir, el Índice de Pobreza Monetaria se disminuiría en $8,88 \%$. Esta disminución se puede percibir en dos momentos, 81.053 personas salen de la pobreza durante la etapa de construcción del año 2016 a 2019 y 463.108 personas abandonan dicha condición a lo largo del periodo de operación del año 2020 al 2024. La disminución en el número de personas pobres medidas por el Índice de Pobreza Multidimensional asciende a 110.236 durante la etapa de inversión, operación y mantenimiento. Se resalta que esta población está asociada a la población pobre extrapolada por el Índice de Pobreza Monetaria, pues se considera que mayores ingresos se asocian con una mejor calidad de vida en términos multidimensionales.

En este documento se cuantificó que, por cada persona pobre medida 
por el Índice de Pobreza Monetaria, hay 0,778 personas pobres medidas por el Índice de Pobreza Multidimensional. A partir de esta razón, y de la aplicación de la metodología presentada en este documento, se estimó que, para la zona de influencia de los departamentos de Caldas, Cauca, Cundinamarca, Huila y Tolima, el Índice de Pobreza Multidimensional en su conjunto pasará de 12,44\% en el año 2016 a 10,22\% en el año 2024, mientras el Índice de Pobreza Monetaria pasa de $32,1 \%$ en 2016 a 23,2\% en el año 2024 .

Tal como se muestra en el estudio de caso, la inversión en infraestructura vial es definitivamente una de las de mayor impacto sobre el crecimiento económico de un país. La contribución se refleja en la reducción de costos generalizados de viaje y mayor desarrollo económico. No obstante, una recomendación muy importante es el tratar de cumplir óptimamente con los planes de inversión (tanto en cumplimiento de tiempos como en otras metas) y operación previstos, un atraso genera altos costos de oportunidad en términos de desarrollo. Los procesos de cierres financieros óptimos, de cumplimiento en tiempo y calidad de las obras mitigan este costo.

\section{REFERENCIAS}

Agencia Nacional de Infraestructura (ANI) (2015), CAPEX y OPEX corredor Santana-Puerto Salgar. ANI. Bogotá: ANI.

Bon, Ranko (2000), Economic Structure and Maturity: Collected Papers in Input-output Modelling and Applications. En R. Bon, Collected Papers in Input-output Modelling and Applications. Londres: Taylor \& Francis Group, Routledge.

Bui, Trinh (2016), A study on the Input-Output System for evaluation of infrastructure development in Vietnam. Kyoto: Kyoto University Research Information Repository.

Burgos, Katherine (2007), Análisis de multiplicadores y elasticidades para la economía Chilena base 2003, mediante un enfoque input-output. Chile.

Clavijo, Sergio (2016), "Cuál será el impacto de las 4G sobre el PIB real?" Comentario económico del día, marzo 1, [Disponible en: http://anif.co/ sites/default/files/uploads/Mar1-16.pdf; Consultado: noviembre 15, 2019].

Consorcio Consultoría Concesiones Viales Colombia (2014), Análisis socioeconómico y costo beneficio. Bogotá.

Consorcio Consultoría Concesiones Viales Colombia (2014), Análisis socioeconómico y costo beneficio Corredor Mocoa - Neiva. Bogotá. 
CSs Constructores, ICA, ALCA (2015), Evaluación económica, social y ambiental de proyectos Corredor 2 Neiva - Girardot. Bogotá.

Departamento Administrativo Nacional de Estadística (DANE) (2005), Metodología de Diseño Muestral Encuesta de Desempeño Institucional. Bogotá: DANE.

DANE (2017), Pobreza Monetaria y Multidimensional en Colombia 2017. Bogotá: DANE.

DANE. (2018), Matriz Utilización Desagregada en Productos Nacionales e Importados. Bogotá: DANE.

Departamento Nacional de Planeación (DNP) (2012), Conpes Social 150 metodologías oficiales y arreglos institucionales para la medición de la pobreza en Colombia. DNP.

DNP (2014), Plan Nacional de Desarrollo 2014-2018. Bogotá: DNP.

DNP (2017), "Pobreza monetaria y multidimensional departamental: necesidad de políticas públicas diferenciadas", Panorámica Regional No. 3.

Eurostat (2008), Eurostat Manual of Supply, Use and Input-Output Tables. Luxembourg: European Communities.

Hanson, Gordon. H. (2005), "Market potential, increasing returns and geographic concentration”, Journal of international economics, Vol. 67, No. 1.

Hernández, Gustavo (2012), "Matrices insumo - producto y análisis de multiplicadores: una aplicación para Colombia”, Revista de Economía Institucional, Vol. 14, No. 26.

Isaza, Jairo Guillermo y Meza, Carlos Arturo (2004), "La demanda de Trabajo: Teoría y Evidencia Empírica para el caso Colombiano”, Revista Equidad y Desarrollo, Vol. 1, No. 2.

Lotero, Jorge., y Londoño, Carlos (2015), Análisis Económico: Autopistas para la Prosperidad. Medellín: Universidad Pontificia Bolivariana y Universidad de Antioquia.

Miller, Ronald y Blair, Peter (2009), Input - Output Analysis: Foundations and Extensions. Cambridge: Cambridge University Press.

Nguyen, Van., y Shimizu, Tesuo (2017), "Input-Output Table for Transportation and Tourism Analysis: Construction and Applications", Journal of the Eastern Asia Society for Transportation Studies, Vol. 12.

Ramírez, Jorge (2018), Foros Semana Vías 4G, Colombia Avanza. (Semana 17 de julio, Entrevistador).

Ramírez, Juan Mauricio y Villar, Leonardo (2014), Infraestructura Regional y Pobreza Rural. Documento de trabajo de Fedesarrollo. 
Ramírez, Juan Mauricio y Villar, Leonardo (2015), Macroeconomía de las Concesiones de Cuarta Generación. Documento de Trabajo de Fedesarrollo. Roda, Pablo; Perdomo, Francisco y Sánchez, Jorge (2015), Impacto de la infraestructura de transporte en el desempeño económico. Archivos de Economía No. 424, Documento de Trabajo del DNP.

Rodríguez, Jesús José (2012), "Determinantes de la demanda de empleo en el sector manufacturero colombiano: 2000-2010”, Lecturas de Economía, No. 79.

Rueda, Jorge Armando (2013), Elasticidad producto del empleo a nivel sectorial para la economía colombiana 2001-2010. Bogotá: Documento de trabajo.

United Nations (2018), Handbook on Supply, Use and Input-Output Tables with Extensions and Applications. Nueva York: United Nations. 


\section{ANEXO A}

Los multiplicadores se determinan por medio de la expresión matricial:

$$
X=Z i+f
$$

Donde:

$\chi$ : Es un vector columna $(n \times 1)$, de oferta de cada una de las $n$ actividades de la economía: agricultura, industria, comercio, entre otros.

Z: Es la matriz $(n \times n)$ de las $n$ actividades de la economía (compras y ventas intermedias).

$i$ : Es un vector columna ( $n \times 1)$, cuyo elemento es el número uno.

$f$ : Es el vector columna $(n \times 1)$ de la demanda final realizada por los hogares, gobierno, inversionistas y exportadores.

Debido a que $Z$ contiene los requerimientos mínimos de insumos para realizar su actividad económica, entonces contempla información sobre la tecnología de cada una de las actividades económicas. Esta tecnología se puede representar de la forma:

$$
A=Z x^{-1}
$$

Donde $\mathrm{x}$ es una matriz diagonal $(n \times n)$ que contiene las demandas totales (intermedias y finales) de cada sector en su diagonal, y A es la matriz ( $\mathrm{n} \times \mathrm{n}$ ) de coeficientes tecnológicos Leontief. De manera alternativa, esta ecuación se puede escribir de la forma:

$$
Z=A x
$$

$\mathrm{Al}$ reemplazar la ecuación (A3) en (A1) y realizar asociaciones, se genera:

$$
(I-A) X=f .
$$

Donde I es la matriz identidad ( $n \times n)$. De esta forma, los multiplicadores $\mathrm{m} \Delta \mathrm{f}$ asociados a la oferta de las diferentes actividades, ante variaciones de la demanda final, se derivan a partir de:

$$
\begin{gathered}
X=(I-A)^{-1} f \\
X=m f \\
\Delta X=m \Delta f .
\end{gathered}
$$


Donde $m=(I-A)^{-1}$ es la matriz inversa de Leontief $(n \times n)$ y cada elemento representa el efecto multiplicador como consecuencia de un cambio unitario en la demanda final (en este caso la inversión).

\section{ANEXO B}

\section{A. Supuesto del crecimiento del salario de los trabajadores}

\section{CUADRO B1}

Valor del salario minimo y variación 2010-2015

\begin{tabular}{|c|c|c|}
\hline Año & Salario mínimo & Variación \\
\hline 2010 & $\$ 515.000$ & \\
\hline 2011 & $\$ 535.600$ & $4,00 \%$ \\
\hline 2012 & $\$ 566.700$ & $5,81 \%$ \\
\hline 2013 & $\$ 589.500$ & $4,02 \%$ \\
\hline 2014 & $\$ 616.000$ & $4,50 \%$ \\
\hline 2010 & $\$ 644.350$ & $4,60 \%$ \\
\hline \multicolumn{2}{|c|}{ Promedio } & $4,59 \%$ \\
\hline
\end{tabular}

Fuente: Elaboración propia. 


\section{B. Supuesto del crecimiento del valor de la línea de la pobreza}

\section{CUADRO B2}

Supuesto 1. Inflación doméstica (IPC), fin de periodo, 2015-2025

\begin{tabular}{|c|c|}
\hline Año & Inflación \\
\hline 2015 & $6,77 \%$ \\
\hline 2016 & $5,75 \%$ \\
\hline 2017 & $4,10 \%$ \\
\hline 2018 & $3,00 \%$ \\
\hline 2019 & $3,00 \%$ \\
\hline 2020 & $3,00 \%$ \\
\hline 2021 & $3,00 \%$ \\
\hline 2022 & $3,00 \%$ \\
\hline 2023 & $3,00 \%$ \\
\hline 2024 & $3,00 \%$ \\
\hline 2025 & $3,00 \%$ \\
\hline
\end{tabular}

Nota: La inflación está proyectada por el DNP hasta el 2022; sin embargo, para completar el periodo de análisis se mantuvo en 3\% para los años 2023 y 2024.

Fuente: Elaboración y cálculos propios, a partir de DNP (2017). 


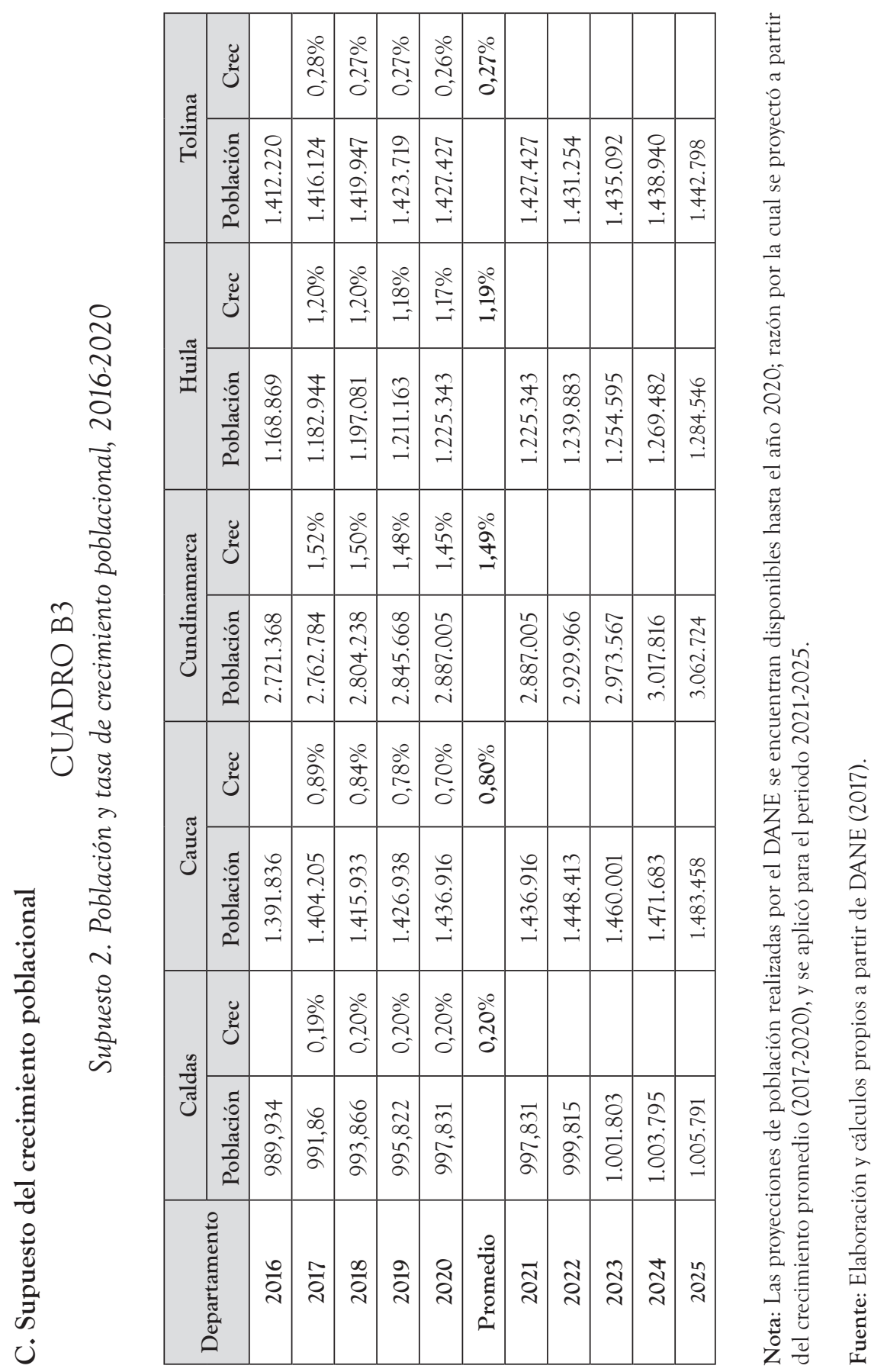




\section{Referencia línea de pobreza}

\section{CUADRO B4}

Proyecciones líneas de pobreza según zona, 2016-2024, pesos colombianos (COP)

\begin{tabular}{|c|c|c|c|c|c|}
\hline Año & Nacional & Cabeceras & $\begin{array}{c}\text { Centros poblados } \\
\text { y rural disperso }\end{array}$ & $\begin{array}{c}13 \text { ciudades y } \\
\text { A.M. }\end{array}$ & Otras Cabeceras \\
\hline 2015 & $\$ 223.638$ & $\$ 246.336$ & $\$ 147.752$ & $\$ 245.856$ & $\$ 247.027$ \\
\hline 2016 & $\$ 236.497$ & $\$ 260.500$ & $\$ 156.248$ & $\$ 259.993$ & $\$ 261.231$ \\
\hline 2017 & $\$ 246.194$ & $\$ 271.181$ & $\$ 162.654$ & $\$ 270.652$ & $\$ 271.942$ \\
\hline 2018 & $\$ 253.579$ & $\$ 279.316$ & $\$ 167.534$ & $\$ 278.772$ & $\$ 280.100$ \\
\hline 2019 & $\$ 261.187$ & $\$ 287.696$ & $\$ 172.560$ & $\$ 287.135$ & $\$ 288.503$ \\
\hline 2020 & $\$ 269.022$ & $\$ 296.327$ & $\$ 177.736$ & $\$ 295.749$ & $\$ 297.158$ \\
\hline 2021 & $\$ 277.093$ & $\$ 305.216$ & $\$ 183.068$ & $\$ 304.622$ & $\$ 306.073$ \\
\hline 2022 & $\$ 285.406$ & $\$ 314.373$ & $\$ 188.560$ & $\$ 313.760$ & $\$ 315.255$ \\
\hline 2023 & $\$ 293.968$ & $\$ 323.804$ & $\$ 194.217$ & $\$ 323.173$ & $\$ 324.712$ \\
\hline 2024 & $\$ 302.787$ & $\$ 333.518$ & $\$ 200.044$ & $\$ 332.868$ & $\$ 334.454$ \\
\hline
\end{tabular}

Fuente: Elaboración y cálculos propios, a partir de DANE (2017) y DNP (2017). 


\section{E. Simulación pobreza monetaria según departamento, 2016-2024}

\section{CUADRO B5}

Población, número de personas pobres e incidencia de la pobreza según departamento, 2016-2024

\begin{tabular}{|c|c|c|c|c|c|c|c|}
\hline \multirow[b]{2}{*}{ Fase } & \multirow[b]{2}{*}{ Año } & \multicolumn{3}{|c|}{ Total, corredor } & \multicolumn{3}{|c|}{ Caldas } \\
\hline & & Población & $\begin{array}{c}\text { Población } \\
\text { pobre }\end{array}$ & $\begin{array}{l}\text { Incidencia } \\
\text { de pobreza }\end{array}$ & Población & $\begin{array}{c}\text { Población } \\
\text { pobre }\end{array}$ & $\begin{array}{l}\text { Incidencia } \\
\text { de pobreza }\end{array}$ \\
\hline \multirow{4}{*}{$\begin{array}{l}\text { Construc- } \\
\text { ción }\end{array}$} & 2016 & 7.626 .797 & 2.463 .845 & $32,3 \%$ & 987.991 & 285.425 & $28,9 \%$ \\
\hline & 2017 & 7.626 .797 & 2.442 .104 & $32,0 \%$ & 987.991 & 280.756 & $28,4 \%$ \\
\hline & 2018 & 7.626 .797 & 2.375 .518 & $31,1 \%$ & 987.991 & 271.139 & $27,4 \%$ \\
\hline & 2019 & 7.626 .797 & 2.322 .469 & $30,5 \%$ & 987.991 & 260.458 & $26,4 \%$ \\
\hline \multirow{5}{*}{ Operación } & 2020 & 7.626 .797 & 2.085 .425 & $27,3 \%$ & 987.991 & 245.089 & $24,8 \%$ \\
\hline & 2021 & 7.626 .797 & 2.037 .994 & $26,7 \%$ & 987.991 & 238.824 & $24,2 \%$ \\
\hline & 2022 & 7.626 .797 & 1.993 .583 & $26,1 \%$ & 987.991 & 230.552 & $23,3 \%$ \\
\hline & 2023 & 7.626 .797 & 1.923 .723 & $25,2 \%$ & 987.991 & 222.495 & $22,5 \%$ \\
\hline & 2024 & 7.626 .797 & 1.856 .600 & $24,3 \%$ & 987.991 & 215.148 & $21,8 \%$ \\
\hline \multirow[b]{2}{*}{ Fase } & \multirow[b]{2}{*}{ Año } & \multicolumn{3}{|c|}{ Cauca } & \multicolumn{3}{|c|}{ Cundinamarca } \\
\hline & & Población & $\begin{array}{c}\text { Población } \\
\text { pobre }\end{array}$ & $\begin{array}{l}\text { Incidencia } \\
\text { de pobreza }\end{array}$ & Población & $\begin{array}{c}\text { Población } \\
\text { pobre }\end{array}$ & $\begin{array}{l}\text { Incidencia } \\
\text { de pobreza }\end{array}$ \\
\hline \multirow{4}{*}{$\begin{array}{l}\text { Construc- } \\
\text { ción }\end{array}$} & 2016 & 1.379 .201 & 720.509 & $52,2 \%$ & 2.696 .566 & 468.707 & $17,4 \%$ \\
\hline & 2017 & 1.379 .201 & 718.797 & $52,1 \%$ & 2.696 .566 & 461.931 & $17,1 \%$ \\
\hline & 2018 & 1.379 .201 & 701.359 & $50,9 \%$ & 2.696 .566 & 442.429 & $16,4 \%$ \\
\hline & 2019 & 1.379 .201 & 688.623 & $49,9 \%$ & 2.696 .566 & 433.664 & $16,1 \%$ \\
\hline \multirow{5}{*}{ Operación } & 2020 & 1.379 .201 & 628.142 & $45,5 \%$ & 2.696 .566 & 375.943 & $13,9 \%$ \\
\hline & 2021 & 1.379 .201 & 616.637 & $44,7 \%$ & 2.696 .566 & 359.786 & $13,3 \%$ \\
\hline & 2022 & 1.379 .201 & 609.662 & $44,2 \%$ & 2.696 .566 & 350.114 & $13,0 \%$ \\
\hline & 2023 & 1.379 .201 & 596,71 & $43,3 \%$ & 2.696 .566 & 326.757 & $12,1 \%$ \\
\hline & 2024 & 1.379 .201 & 581.269 & $42,1 \%$ & 2.696 .566 & 309.052 & $11,5 \%$ \\
\hline
\end{tabular}

Fuente: Elaboración y cálculos propios, a partir de GEIH (2005), DANE (2017) y DNP (2017). 


\section{CUADRO B5(Continuación)}

Población, número de personas pobres e incidencia de la pobreza según departamento, 2016-2024

\begin{tabular}{|c|c|c|c|c|c|c|c|}
\hline \multirow{4}{*}{ Fase } & \multirow{2}{*}{ Año } & \multicolumn{4}{|c|}{ Huila } & \multicolumn{3}{c|}{ Tolima } \\
\cline { 3 - 8 } & & Población & $\begin{array}{c}\text { Población } \\
\text { pobre }\end{array}$ & $\begin{array}{c}\text { Incidencia } \\
\text { de pobreza }\end{array}$ & Población & $\begin{array}{c}\text { Población } \\
\text { pobre }\end{array}$ & $\begin{array}{c}\text { Incidencia de } \\
\text { pobreza }\end{array}$ \\
\hline \multirow{4}{*}{$\begin{array}{c}\text { Construc- } \\
\text { ción }\end{array}$} & 2016 & 1.154 .769 & 515.748 & $44,7 \%$ & 1.408 .270 & 473.455 & $33,6 \%$ \\
\cline { 2 - 8 } & 2017 & 1.154 .769 & 513.702 & $44,5 \%$ & 1.408 .270 & 466.918 & $33,2 \%$ \\
\cline { 2 - 8 } & 2018 & 1.154 .769 & 504.202 & $43,7 \%$ & 1.408 .270 & 456.389 & $32,4 \%$ \\
\cline { 2 - 8 } & 2019 & 1.154 .769 & 497.392 & $43,1 \%$ & 1.408 .270 & 442.332 & $31,4 \%$ \\
\hline \multirow{4}{*}{ Operación } & 2020 & 1.154 .769 & 453.894 & $39,3 \%$ & 1.408 .270 & 386.357 & $27,4 \%$ \\
\cline { 2 - 8 } & 2021 & 1.154 .769 & 448.784 & $38,9 \%$ & 1.408 .270 & 373.964 & $26,6 \%$ \\
\cline { 2 - 8 } & 2022 & 1.154 .769 & 443.499 & $38,4 \%$ & 1.408 .270 & 359.756 & $25,5 \%$ \\
\cline { 2 - 8 } & 2023 & 1.154 .769 & 429.772 & $37,2 \%$ & 1.408 .270 & 347.988 & $24,7 \%$ \\
\cline { 2 - 8 } & 2024 & 1.154 .769 & 416.597 & $36,1 \%$ & 1.408 .270 & 334.533 & $23,8 \%$ \\
\hline
\end{tabular}

Fuente: Elaboración y cálculos propios, a partir de GEIH (2005), DANE (2017) y DNP (2017).

\section{F. Población pobreza monetaria y multidimensional 2015}

\section{CUADRO B6}

Población pobre monetaria y multidimensional 2015

\begin{tabular}{|c|c|c|c|}
\cline { 2 - 4 } \multicolumn{1}{c|}{} & Pobres Monetarios & $\begin{array}{c}\text { Pobres } \\
\text { Multidimensionales }\end{array}$ & $\begin{array}{c}\text { Relación pobres } \\
\text { multidimensionales } \\
\text { pobres monetarios }\end{array}$ \\
\hline Caldas & 275,776 & 159,007 & 0,577 \\
\hline Cauca & 711,67 & 523,045 & 0,735 \\
\hline Cundinamarca & 458,52 & 539,174 & 1.176 \\
\hline Huila & 511,158 & 260,224 & 0,509 \\
\hline Tolima & 464,018 & 402,56 & 0,868 \\
\hline Total & 2.421 .142 & 1.884 .011 & 0,778 \\
\hline
\end{tabular}

Fuente: Elaboración y cálculos propios a partir de GEIH (2015). 


\section{ANEXO C}

\section{A. Modelo gravitacional}

El modelo gravitacional tiene como objetivo estimar impactos sobre el PIB per cápita e ingresos tributarios asociados a las menores distancias, como consecuencia de la puesta en operación de los proyectos 1, 2 y 3. La distancia en este caso se mide en disminuciones por proyecto. Debido a que el corredor no está finalizado y la información suministrada no es exacta, se proponen 3 escenarios de $10 \mathrm{~km}$ en un escenario conservador, $20 \mathrm{~km}$ según uno moderado y $50 \mathrm{~km}$ en uno optimista. Cada uno de estos indicadores se examina por medio de un Modelo Gravitacional con Datos de Corte Transversal.

\section{Modelo gravitacional según proyecto}

La disminución en la distancia permite reducir los costos operacionales vehiculares y el tiempo de viaje, factores que a su vez aumentan el flujo vehicular y el recaudo del ICA (lo que es equivalente a mayor comercio), al igual que el impuesto Predial (lo que es equivalente a valorización como consecuencia de construcción o ampliación de la vía), y concretan un mayor PIB per cápita (aproximado por el VA per cápita) para cada municipio según proyecto. Para el caso del proyecto 1, el impacto derivado de estos indicadores se extrae de los cuadros que se presentan a continuación para el caso del PIB per cápita. Los indicadores que controlan cada una de estas ecuaciones son la Productividad $\left(\text { Pro }_{i}\right)^{17}$ y la Tasa de Mortalidad (Mor ${ }_{i}$ en términos logarítmicos.

${ }^{17}$ La productividad se define como el rendimiento promedio por hectárea de los cinco principales productos del departamento según lo reporta Agronet. 


\section{CUADRO C1}

Incremento porcentual en PIB per cápita del proyecto 1 por reducción en la distancia

\begin{tabular}{|c|c|}
\hline \multicolumn{2}{|c|}{ Estimación por: $\mathrm{MCO}^{*}$} \\
\hline \multicolumn{2}{|c|}{ Ln (PIB per cápita $\left.{ }_{\mathrm{i}, \mathrm{t}}\right)$} \\
\hline Variable & Coeficiente \\
\hline \multirow{2}{*}{ Ln(Predial $\left.{ }_{\mathrm{i}^{\prime} \mathrm{t}}\right)$} & $0,510^{* * * *}$ \\
\hline & $(0,139)$ \\
\hline \multirow{2}{*}{ Ln(Población $\left.{ }_{i, t}\right)$} & $-0,802^{* * * *}$ \\
\hline & $(0,098)$ \\
\hline \multirow{2}{*}{ Distancia $_{\mathrm{i}, \mathrm{t}}$} & $-0,002^{* *}$ \\
\hline & $(0,001)$ \\
\hline
\end{tabular}

\begin{tabular}{|c|c|}
\hline \multicolumn{2}{|c|}{ Estimación por: $\mathrm{MCO}$} \\
\hline \multicolumn{2}{|c|}{ Ln (PIB per cápita ${ }_{\mathrm{i}}{ }_{\mathrm{t}}$ ) } \\
\hline Variable & Coeficiente \\
\hline \multirow{2}{*}{$\operatorname{Ln}\left(\right.$ Pro $\left._{\mathrm{i}, \mathrm{t}}\right)$} & $0,39^{*}$ \\
\cline { 2 - 2 } & $(0,387)$ \\
\hline \multirow{2}{*}{ Mor $_{\mathrm{i}, \mathrm{t}}$} & $-0,013^{*}$ \\
\cline { 2 - 2 } & $(0,035)$ \\
\hline \multirow{2}{*}{ Distancia $_{\mathrm{i}, \mathrm{t}}$} & $-0,001^{*}$ \\
\cline { 2 - 2 } & $(0,003)$ \\
\hline \multirow{2}{*}{ Constante $^{*}$} & $-4,32^{* * * *}$ \\
\cline { 2 - 2 } & $(0,619)$ \\
\hline
\end{tabular}

Nota: Entre paréntesis la desviación estándar. ${ }^{* * *}$ Pvalue $\leq 0,01 ;{ }^{* * *}$ Pvalue $\leq 0,05$; ** Pvalue $\leq$ 0,$1 ;{ }^{*}$ Pvalue $>0,1$

Fuente: Elaboración propia en Stata 13.1.

Tomando los resultados del cuadro $\mathrm{C} 1$, si disminuye la distancia en $10 \mathrm{~km}$ y se mantiene las otras variables constantes, se espera que se presente un aumento hasta del $2 \%\left(0,002 * 10^{*} 100=2,0 \%\right)$ como se observa en el Cuadro C2. 


\section{CUADRO C2}

Impacto por reducción en la distancia, proyecto 1

\begin{tabular}{|c|c|c|c|}
\hline $\begin{array}{c}\text { Disminución en la } \\
\text { distancia }\end{array}$ & $\begin{array}{c}\text { Crecimiento ICA } \\
\text { municipal }\end{array}$ & $\begin{array}{c}\text { Crecimiento Predial } \\
\text { Municipal }^{*}\end{array}$ & $\begin{array}{c}\text { Crecimiento PIB } \\
\text { per cápita } \\
\text { municipal }^{*}\end{array}$ \\
\hline $\begin{array}{c}\text { Escenario } \\
\text { pesimista } 10 \mathrm{~km}\end{array}$ & $0 \%$ y $3,0 \%$ & $0 \%$ y $3,0 \%$ & $0 \%$ y $2,0 \%$ \\
\hline $\begin{array}{c}\text { Escenario } \\
\text { tendencial } 20 \mathrm{~km}\end{array}$ & $0 \%$ y $6,0 \%$ & $0 \%$ y $6,0 \%$ & $0 \%$ y $4,0 \%$ \\
\hline $\begin{array}{c}\text { Escenario } \\
\text { optimista } 50 \mathrm{~km}\end{array}$ & $0 \%$ y $15,0 \%$ & $0 \%$ y $12,0 \%$ & $0 \%$ y $10,0 \%$ \\
\hline
\end{tabular}

Nota: *El rango se extrae con un intervalo de confianza del 95\%.

Fuente: Elaboración propia con base en la información suministrada por el DNP y DANE, y calculada en Stata. 13.1.

Para el caso de los proyectos 2 y 3 se presentan los cuadros resumen, debido a que la metodología es similar a la presentada para el proyecto 1 .

\section{CUADRO C3}

Impactos por reducción en la distancia proyecto 2

\begin{tabular}{|c|c|c|c|}
\hline $\begin{array}{c}\text { Disminución en la } \\
\text { distancia }\end{array}$ & $\begin{array}{c}\text { Crecimiento ICA } \\
\text { municipal }^{*}\end{array}$ & $\begin{array}{c}\text { Crecimiento Predial } \\
\text { Municipal }^{*}\end{array}$ & $\begin{array}{c}\text { Crecimiento PIB } \\
\text { per cápita } \text { municipal }^{*}\end{array}$ \\
\hline $\begin{array}{c}\text { Escenario } \\
\text { pesimista } 10 \mathrm{~km}\end{array}$ & $0 \%$ y $2,0 \%$ & $0 \%$ y $2,0 \%$ & $0 \%$ y $1,0 \%$ \\
\hline $\begin{array}{c}\text { Escenario } \\
\text { tendencial } 20 \mathrm{~km}\end{array}$ & $0 \%$ y $4,0 \%$ & $0 \%$ y $4,0 \%$ & $0 \%$ y $2,0 \%$ \\
\hline $\begin{array}{c}\text { Escenario } \\
\text { optimista } 50 \mathrm{~km}\end{array}$ & $0 \%$ y $10,0 \%$ & 0 y $10,0 \%$ & $0 \%$ y $5,0 \%$ \\
\hline
\end{tabular}

Nota: *El rango se extrae con un intervalo de confianza del 95\%.

Fuente: Elaboración propia con base a la información suministrada por el DNP y DANE, y calculada en Stata. 13.1. 


\section{CUADRO C4}

Impactos por reducción en la distancia proyecto 3

\begin{tabular}{|c|c|c|c|}
\hline $\begin{array}{c}\text { Disminución en la } \\
\text { distancia }\end{array}$ & $\begin{array}{c}\text { Crecimiento ICA } \\
\text { municipal }\end{array}$ & $\begin{array}{c}\text { Crecimiento Predial } \\
\text { Municipal }\end{array}$ & $\begin{array}{c}\text { Crecimiento PIB } \\
\text { per cápita } \\
\text { municipal }\end{array}$ \\
\hline $\begin{array}{c}\text { Escenario } \\
\text { pesimista } 10 \mathrm{~km}\end{array}$ & $0 \%$ y $0,3 \%$ & $0 \%$ y $1,0 \%$ & $0 \%$ y $1,0 \%$ \\
\hline $\begin{array}{c}\text { Escenario } \\
\text { tendencial } 20 \mathrm{~km}\end{array}$ & $0 \%$ y $0,6 \%$ & $0 \%$ y $2,0 \%$ & $0 \%$ y $2,0 \%$ \\
\hline $\begin{array}{c}\text { Escenario } \\
\text { optimista } 50 \mathrm{~km}\end{array}$ & $0 \%$ y $1,5 \%$ & $0 \%$ y $5,0 \%$ & $0 \%$ y $5,0 \%$ \\
\hline
\end{tabular}

Nota: *El intervalo se extrae bajo un intervalo de confianza del 95\%.

Fuente: Elaboración propia. Stata. 13.1. 